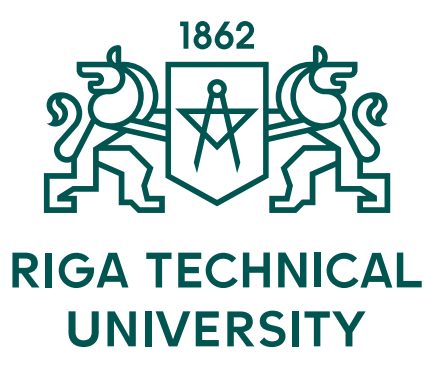

Zane Broka

\title{
HARNESSING THE VALUE OF DEMAND-SIDE FLEXIBILITY IN ELECTRICITY MARKETS
}

Summary of the Doctoral Thesis 


\section{RIGA TECHNICAL UNIVERSITY}

Faculty of Electrical and Environmental Engineering Institute of Power Engineering

\section{Zane Broka}

Doctoral Student of the Study Programme "Power and Electrical Engineering"

\section{HARNESSING THE VALUE OF DEMAND-SIDE FLEXIBILITY IN ELECTRICITY MARKETS}

Summary of the Doctoral Thesis

Scientific supervisor Professor Dr. habil. sc. ing. ANTANS SAUHATS 
Broka, Z. Harnessing the Value of DemandSide Flexibility in Electricity Markets. Summary of the Doctoral Thesis. Riga: RTU Press, 2020. 50 p.

Published in accordance with the decision of the Promotion Council "RTU P-05" of 28 September 2020 No. 79/20.

Part of the research within the Doctoral Thesis was funded by the Ministry of Economics of the Republic of Latvia, project "Futureproof development of the Latvian power system in an integrated Europe (FutureProof)", project No. VPP-EM-INFRA-2018/1-0005.

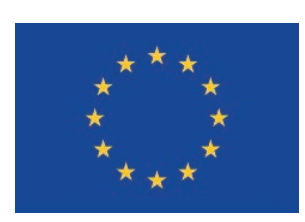

Part of the research in the Doctoral Thesis was conducted within the RealValue project. This project received funding from the European Union's Horizon 2020 research and innovation programme under grant agreement No 646116.

https://doi.org/10.7250/9789934225154

ISBN 978-9934-22-514-7 (print)

ISBN 978-9934-22-515-4 (pdf) 


\section{DOCTORAL THESIS PROPOSED TO RIGA TECHNICAL UNIVERSITY FOR THE PROMOTION TO THE SCIENTIFIC DEGREE OF DOCTOR OF SCIENCE}

To be granted the scientific degree of Doctor of Science (Ph. D.), the present Doctoral Thesis has been submitted for the defence at the open meeting of RTU Promotion Council on November 12, 2020 at 11:30 at the Faculty of Electrical and Environmental Engineering of Riga Technical University, 12 k-1 Azenes Street, Room 306.

\section{OFFICIAL REVIEWERS}

Associate Professor Dr. sc. ing. Anna Mutule

Riga Technical University, Latvia

Lead Planning Engineer Dr. sc. ing. Julia Matevosyan

Electric Reliability Council of Texas (ERCOT), United States

Professor Dr. sc. ing. Saulius Gudžius

Kaunas University of Technology, Lithuania

\section{DECLARATION OF ACADEMIC INTEGRITY}

I hereby declare that the Doctoral Thesis submitted for the review to Riga Technical University for the promotion to the scientific degree of Doctor of Science (Ph. D.) is my own. I confirm that this Doctoral Thesis has not been submitted to any other university for the promotion to a scientific degree.

Zane Broka (signature)

Date

The Doctoral Thesis has been written in English. It consists of an introduction; four chapters; conclusions; 84 figures; 21 table; five appendices; the total number of pages is 170 . The bibliography contains 117 titles. 


\section{CONTENTS}

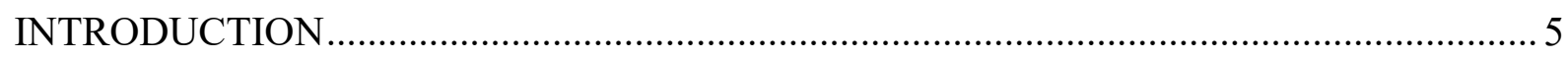

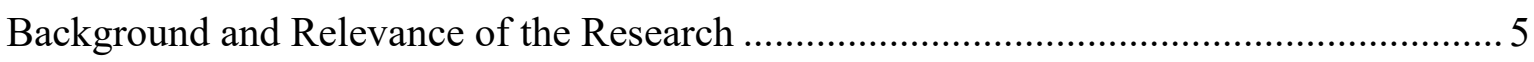

Hypothesis, Objective and Tasks of the Thesis ............................................................... 7

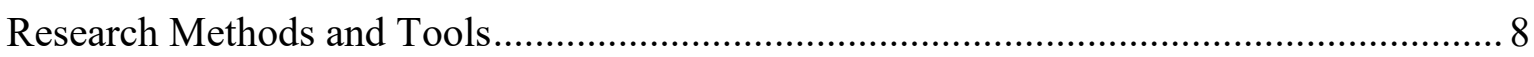

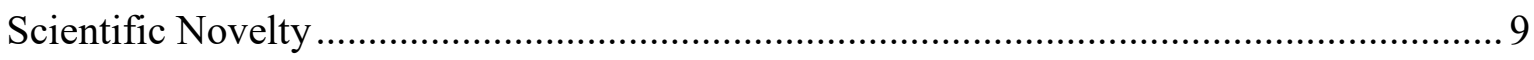

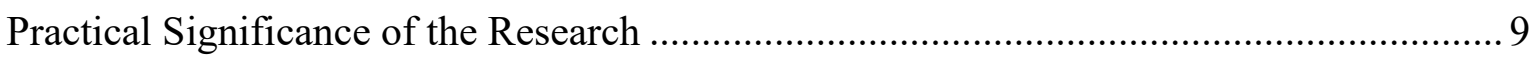

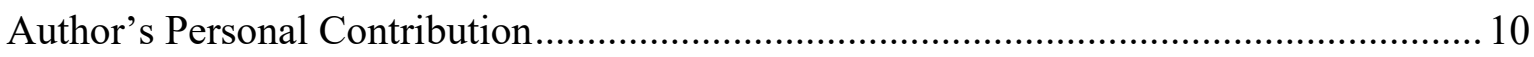

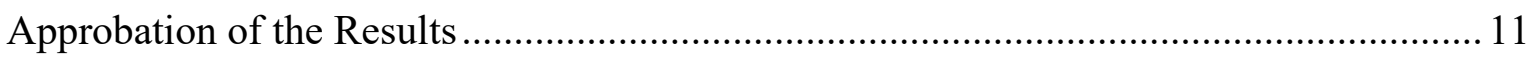

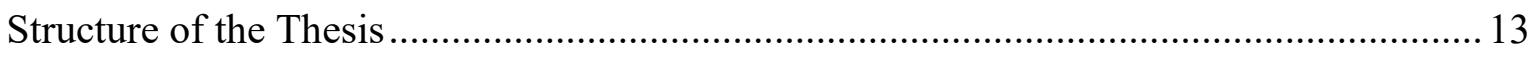

1. OPTIMAL ACTIVATION OF BALANCING RESERVES .......................................... 14

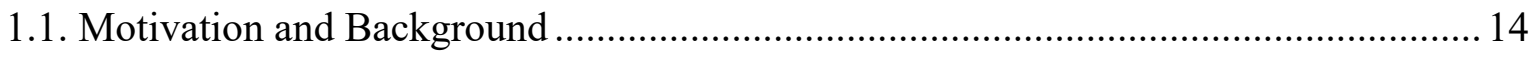

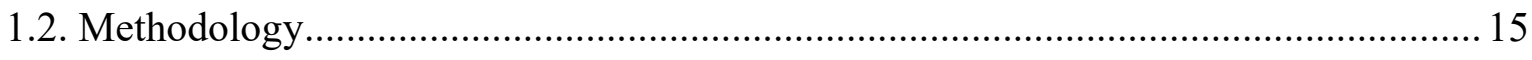

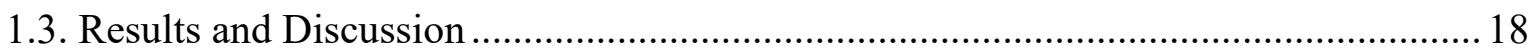

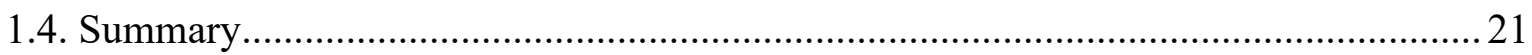

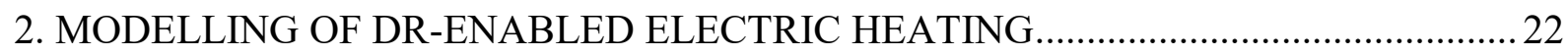

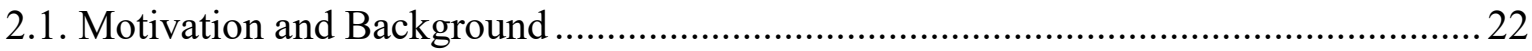

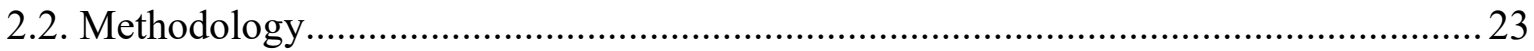

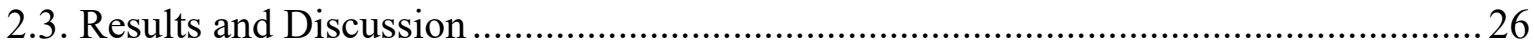

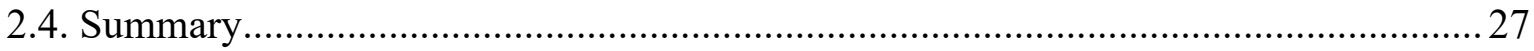

3. VALUE ESTIMATION OF SETS AS A DR-ENABLED RESOURCE …...................... 28

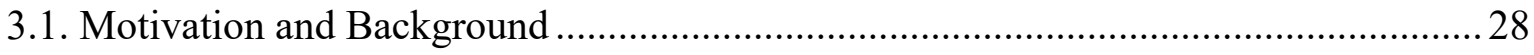

3.2. Modelling of SETS Impact on the Distribution Grid …................................................ 29

3.3. Modelling of SETS Impact on the Power System ...................................................... 32

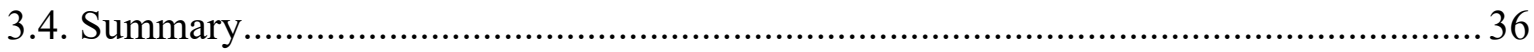

4. ECONOMIC ASSESSMENT OF RESIDENTIAL-SCALE DR …................................. 37

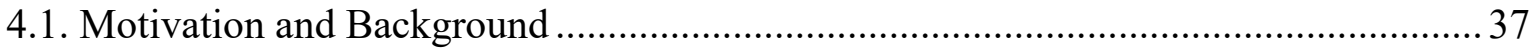

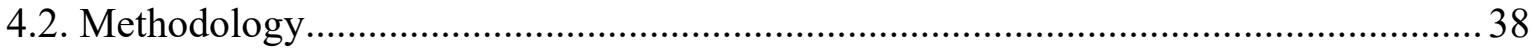

4.3. Case Study on Participation of Residential DR in Balancing Market .......................... 39

4.4. Case Study on the Benefits of Explicit and Implicit DR .......................................... 42

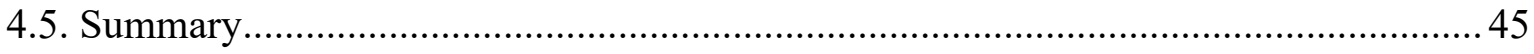

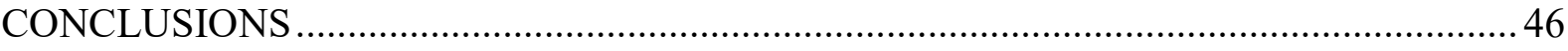

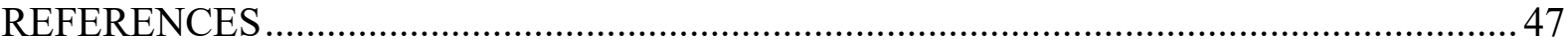




\section{INTRODUCTION}

\section{Background and Relevance of the Research}

The action plan for development of electricity market in the Baltic states and integrating it into the wider EU energy market was formally established by the Baltic Energy Market Interconnection Plan (BEMIP) in 2009 [1], [2]. As a result of the BEMIP implementation, the wholesale power markets of the three Baltic states have been well coupled with the Nordic countries by joining the Nord Pool power exchange in 2010 (Estonia), 2012 (Lithuania) and 2013 (Latvia) respectively [3]. Now, electricity producers and traders from the Baltic states successfully operate in both day-ahead and intraday market of the Nord Pool where the majority of wholesale transactions take place.

Nevertheless, the Baltic power system still has some distinct characteristics from the rest of Europe due to its synchronous operation with the Integrated/Unified Power System (IPS/UPS) of Russia and Belarus. The Russian power system provides primary power reserves for frequency regulation and secure system operation within the BRELL (Belarus, Russia, Estonia, Latvia, and Lithuania) ring [4]. The synchronous operation of the Baltic states with the IPS/UPS is planned to be terminated by $\mathbf{2 0 2 5}$ which is the deadline to complete the synchronisation of the Baltic power grid with the Continental Europe network [5].

However, in order to increase the energy independence of the Baltic states and involve more local balancing resources in power system regulation already several years before the planned desynchronisation, the TSOs of Latvia, Estonia, and Lithuania launched a common Baltic balancing market in 2018 within which the three countries are able to share balancing energy [6]. Furthermore, the growing share of intermittent generation sources, especially wind power plants, combined with the planned synchronisation of the Baltic power systems with the Continental Europe grid, only increases the demand for balancing resources and improved flexibility of the power system to be able to ensure frequency regulation not only during normal conditions but also in case of major outages and even in islanding mode [7].

Flexibility of the power system is its ability "to accommodate the variability and uncertainty in the load-generation balance" [8]. Generally, most of the flexibility today is provided by the conventional power plants; nevertheless, it is also possible to harvest flexibility from demand-side resources, the potential of which has been recognised, though still remains underexploited [8]. Demand response (DR) has become a particularly attractive option for increasing power system flexibility with the recent advances in IT, control and forecasting tools and techniques [9]. Moreover, the advancement of DR fortunately coincides with the increasing penetration of renewable generation largely composed of variable and intermittent energy sources calling for more and more flexibility in the power system.

It should be noted though that systematic load shedding is recognised as the most obvious form of demand response employed in various forms worldwide for decades as a last resort to avoid system blackout [9]. However, the recent evolvement of a vast array of IT tools and techniques has enabled the advancement of much more sophisticated forms for demand response. Thus, nowadays in many power systems worldwide, demand-side resources can 
participate in balancing of the power system on a par with generation-side, including largescale storage. It is acknowledged that, through provision of flexibility, demand response could bring a wide range of benefits and thus constitute one of the main components of the smart grid [10]. Notwithstanding, there are also a number of challenges related to the involvement of the still untapped demand-side resources in everyday control actions of the power systems.

European Commission Smart Grid Task Force has defined demand-side flexibility as "the changes in energy usage by end-use customers (domestic and industrial) from their current/normal consumption patterns in response to market signals, such as time-variable electricity prices or incentive payments, or in response to acceptance of the consumer's bid, alone or through aggregation, to sell demand reduction/increase at a price in organized electricity markets" [11]. Similarly, demand response (DR) is defined as "voluntary changes by end-consumers or producers or at storages of their usual electricity/gas flow patterns" [11].

On the one hand, the source of this flexibility is either industrial, commercial or domestic consumers [12] who may use their consumption elasticity or some form of distributed generation and storage. On the other hand, there is a range of possible procurers of flexibility services, including TSOs, DSOs and suppliers, who might use it for balancing of the power system (TSOs), congestion management of the grid (DSOs) or their own portfolio balancing (suppliers) [11]. As a result, three main types of benefits from DR can be distinguished [9]:

- operating benefits by balancing the fluctuations (forecast errors) of intermittent renewables, such as wind generation. It is considered that reliability of demand for provision of ancillary services may be even larger than that from conventional generators and, also, the effective ramping rate of aggregated demand might be much higher [9];

- planning benefits by reducing the capacity requirements of the system due to employment of DR so that investments in both network reinforcement or generation capacity are deferred or avoided [9], [12];

- economic benefits by decreasing the market power of producers and reducing the average wholesale electricity prices [9], [13].

However, in order to be able to actually receive those benefits, there are a number of challenges to be solved beforehand. Apart from other factors, the challenges involved depend on the type of DR. To this end, two main categories of DR can be distinguished:

- implicit DR or indirect load control whereby consumers react to dynamic market price or network tariff signals [14];

- explicit DR or direct load control whereby (usually) aggregated demand-side resources are traded in the wholesale, balancing and capacity markets and consumers are rewarded when changing their consumption upon request for activation of balancing energy or congestion management in the network [14].

Important to note that both forms of DR are needed to accommodate different types of consumers and loads and "exploit the full spectrum of consumer and system benefits" [14].

Some of the main challenges for implementation of DR [9] are as follows: lack of appropriate market mechanisms and regulatory framework; difficulty in establishing a business case for DR and/or DR aggregator; difficulties in establishing DR as a valuable resource; and end-user behaviour. All these challenges can be directly related also to the 
Latvian power system where demand response, properly implemented and integrated into the system, could serve as a valuable resource in providing the required additional flexibility.

The concept of DR and its employment as a power system flexibility source has been reviewed in a large number of scientific papers addressing the overall benefits, challenges, barriers, and enablers [15]-[18] as well as country-specific case studies [19]-[22]. However, this Doctoral Thesis provides an assessment of measures that could increase the flexibility of power systems by employing different types of demand response sources and, additionally, by improving the overall system balancing process. To that end, we start with the latter by proposing an optimised activation strategy of reserves and then move on with assessment of the obtainable operating, planning, and economic benefits from demand response in the power system by providing detailed modelling of a residential DR-enabled power-to-heat $(\mathrm{P} 2 \mathrm{H})$ technology for the Latvian case study. The specific type of technology has been selected considering that $\mathrm{P} 2 \mathrm{H}$ exhibits "large and predictable capacities of DR" compared to smart electric appliances [23]. Furthermore, the Thesis contributes to establishing a business case of DR with a robust tool for an economic assessment of DR from the end-user point-of-view. The knowledge of possible benefits could potentially attract new market participants to the Baltic balancing market, thus increasing market liquidity and improving the overall system flexibility. Hence, the Doctoral Thesis provides a vast array of tools and methods on establishing the value of demand response in the Baltic power system.

\section{Hypothesis, Objective and Tasks of the Thesis}

\section{Hypothesis}

To sustain the growing needs for power system flexibility, demand response can be employed as a valuable resource able to bring benefits both for the power system as a whole and for the end-users providing it. Additionally, power system flexibility can be improved through optimisation of the balancing process, thus promoting efficient use of the available reserves both cost-wise and energy-wise.

\section{Objective}

Cost-benefit assessment of demand response deployment, considering its implications both on the power system, including distribution grid, and end-users providing it, and development of a strategy for optimal activation of balancing resources in the Baltic power system.

\section{Tasks}

1. To develop methodology and a software tool for optimising the activation process of balancing resources within the common Baltic balancing market framework.

2. To devise building thermal models for estimation of their heating demand (provided by DR-enabled electric heating).

3. To study the potential impact and benefits of large-scale deployment of DR-enabled technologies such as smart electric thermal storage in the Latvian power system.

4. To develop methodology and a software tool for probabilistic cost-benefit assessment of demand response provision from the DR asset owner point-of-view. 


\section{Research Methods and Tools}

Research studies presented in the Doctoral Thesis were performed employing various bespoke modelling tools and algorithms developed in-house at the RTU Institute of Power Engineering by Thesis author together with other Institute staff members.

For defining and solving the optimisation problem of the AOF parameter search tool presented in Chapter 1, MATLAB scripting environment and Global Optimization Toolbox was used to take advantage of its data processing abilities and solver patternsearch. Consequently, a stand-alone application was compiled, which can be deployed on a standard computer with the royalty-free MATLAB Runtime environment. Microsoft Excel was used for data input and output due to its user-friendly interface. Additionally, validation and analysis of the results obtained by the optimiser also take place in Excel to enable the user to manually inspect the dynamics of ACE forecast and the course of regulation activations in any particular hour in the test dataset.

Building thermal network models introduced in Chapter 2 were devised in MATLAB Simscape, which enables creation of models of physical systems (buildings in our case) and simulation of their thermal performance using MATLAB Simulink. Thus, MATLAB environment was used both for identification of equivalent thermal network parameters and building simulations to derive their heating demand timeseries for power system modelling in the next chapter. Performance of the simplified thermal network was compared against the results of a more complex EnergyPlus-calibrated model developed by our partners within the RealValue project. For physical experiments in the buildings, temperature loggers were used to derive the cooling and heating curves of the houses.

In Chapter 3, MATLAB was used for power flow modelling in the distribution grid. Solvers from its Optimization Toolbox were employed for optimal load scheduling based on different objectives. Namely, for minimisation of load variance and minimising the cost of losses, fmincon solver (employing the interior-point algorithm) was used which is intended for constrained nonlinear optimisation problems. However, energy cost minimisation, being a linear problem, was performed with the linprog solver using the dual-simplex algorithm.

Furthermore, for power system modelling, the RTU's in-house developed scheduling tool OptiBidus-TEC was employed to derive electricity production schedules for two major cogeneration plants. When modelling the different future scenarios, MATLAB was employed to prepare the input data by scaling and adjusting the data according to the scenario assumptions. Furthermore, the concluding power system benefit assessment was implemented in Excel. It also involved employment of the method of least squares for linear regression.

Similarly to the approach used in Chapter 1, DR Assess tool presented in Chapter 4 was developed using the MATLAB scripting environment. To make it usable for any interested person, a stand-alone application was compiled, which can be deployed on a standard computer with the royalty-free MATLAB Runtime environment. Additionally, due to its user-friendly interface, Microsoft Excel was used for data input and output of detailed results for exemplary scenarios. They allow studying each demand response activation of the scenario and related cash flows in high detail. 


\section{Scientific Novelty}

To facilitate optimal activation of balancing resources by the transmission system operator, a bespoke tool, AOF parameter search, has been developed. It includes a complex algorithm mimicking the activities of a TSO dispatch operator in ordering mFRR products to sustain the power system balance. However, in contrast to solely human-based dispatching of reserves, the proposed algorithm allows automated processing of a large amount of historic data to devise an optimal strategy for the power system regulation process. The optimised regulation parameters provide more efficient power system balancing both energy- and cost-wise and allows reducing the area control error of the Baltic power system towards the Open Balance Provider, thus improving the energy independence of the Baltic states.

Subsequent research efforts have been dedicated to the cost-benefit assessment of various demand-side flexibility resources that can be used not only for power system balancing (via explicit DR) but also for other services or purposes such as implicit DR. To carry out this evaluation from different angles and consider the benefits both from the power system and end-user point-of-view, several mathematical models have been devised.

Firstly, an efficient data-driven modelling approach has been implemented for thermal modelling of buildings in order to estimate their heating demand. This is vital to enable costbenefit assessment of DR-enabled electric heating equipment with thermal storage (smart electric thermal storage heaters, SETS), which is a technology potentially able to provide a number of benefits both for the power system at large and the end-users. The simulated timeseries of building heating demand are then fed into distribution grid and power system models tailored particularly for studying the impact of SETS deployment on the Latvian power system. While this type of heating has been in use in several European countries for decades, it has been virtually unknown in the Latvian market before. To that end, the conducted study is the first one providing insights into the implications of SETS deployment in Latvia. Furthermore, the study was informed by the data obtained through real-life demonstration of SETS in 50 different buildings around Latvia.

Finally, to inform the potential DR-providing end-users of the related costs and benefits, the DR Assess tool has been developed. It is based on Monte Carlo simulations to properly consider the uncertainties characteristic to electricity markets and provide probabilistic results on benefits the end-user can gain through provision of explicit DR to the market or via implementing implicit DR. While the tool has been tailored for the Latvian case, considering the existing common Baltic balancing market and Nord Pool day-ahead market frameworks, it could be easily applied also to other case studies with similar market setup.

\section{Practical Significance of the Research}

Research studies carried out by the author during development of the Doctoral Thesis have contributed to several research and innovation projects. Listed below, they include not only national and international scientific projects but also contract work for a major industry stakeholder. 
1. National Research Programme project "Energy-efficient and low-carbon solutions for a secure, sustainable and climate variability reducing energy supply (LATENERGI)" (2014-2017).

2. Project "Realising Value from Electricity Markets with Local Smart Electric Thermal Storage Technology (RealValue)" (2015-2018), funded within the European Union's Horizon 2020 research and innovation programme.

3. Research contract "Development of mathematical models for an economic assessment of demand-side flexibility resources and activation optimisation of balancing reserves" (2017-2018), commissioned by “Augstsprieguma tīkls” AS (the Latvian TSO).

4. Project "Management and Operation of an Intelligent Power System (I-POWER)" (2018-2021), funded by the Latvian Council of Science.

5. Project "Future-proof development of the Latvian power system in an integrated Europe (FutureProof)" (2018-2021), funded by the Ministry of Economics of the Republic of Latvia within the National Research Programme "Energy".

6. Project "Innovative smart grid technologies and their optimization (INGRIDO)" (2018-2021), funded by the Ministry of Economics of the Republic of Latvia within the National Research Programme "Energy".

7. Project "TSO-DSO-Consumer INTERFACE aRchitecture to provide innovative grid services for an efficient power system (INTERRFACE)" (2019-2022), funded within the European Union's Horizon 2020 research and innovation programme.

\section{Author's Personal Contribution}

During development of the Doctoral Thesis its author participated in several collaborative projects implying tight cooperation with other staff members of the RTU Institute of Power Engineering.

Namely, the $A O F$ parameter search tool was developed by the author together with Researcher K. Baltputnis, under the supervision of Prof. A. Sauhats. The author contributed to all stages of work and specifically to state-of-the-art analysis, conceptualisation, and definition of the mathematical model, data collection, and analysis, took part in programming and testing of the tool, performed the case studies and analysed their results.

Modelling of DR-enabled electric heating and its value estimation for the Latvian power system was performed by the author together with Researcher K. Baltputnis, Senior Researchers J. Kozadajevs and L. Petričenko, under supervision of Prof. A. Sauhats and coordinated by Senior Researcher D. Žalostība. The author contributed to the state-of-the-art analysis, conceptualisation of the models, and methodology, took part in programming and testing of the models as well as in data collection and analysis. The author also interpreted and analysed the results of performed case studies.

Finally, the DR Assess tool was developed by the author in close collaboration with Researcher K. Baltputnis, under the supervision of Prof. A. Sauhats. The author contributed to the state-of-the-art analysis, conceptualisation and definition of the mathematical model, took part in programming and testing of the tool, and analysed the case study results. 


\section{Approbation of the Results}

Research results of the Doctoral Thesis have been included in eight peer-reviewed scientific papers which have been published in the proceedings of six international conferences, all indexed in Scopus.

\section{Scientific paper related to Chapter 1}

1. Broka, Z., Baltputnis, K., Sauhats, A., Junghāns, G., Sadoviča, L., Lavrinovičs, V. Towards Optimal Activation of Balancing Energy to Minimize Regulation from Neighboring Control Areas. In: 2018 15th International Conference on the European Energy Market (EEM 2018), Poland, Lodz, 27-29 June 2018. Piscataway: IEEE, 2018, pp. 1042-1046. ISBN 978-1-5386-1489-1. doi:10.1109/EEM.2018.8469935.

\section{Scientific papers related to Chapter 2}

2. Broka, Z., Kozadajevs, J., Sauhats, A., Finn, D., Turner, W. Modelling Residential Heat Demand Supplied by a Local Smart Electric Thermal Storage System. In: 2016 57th International Scientific Conference on Power and Electrical Engineering of Riga Technical University (RTUCON 2016): Proceedings, Latvia, Riga, 13-14 October 2016. Piscataway, NJ: IEEE, 2016, pp. 259-266. ISBN 978-1-5090-3732-2. e-ISBN 978-1-5090-3731-5. doi:10.1109/RTUCON.2016.7763128.

3. Kozadajevs, J., Broka, Z., Sauhats, A. Modelling Heat Demand in Buildings with an Experimental Approach. In: 2017 IEEE International Conference on Environment and Electrical Engineering and 2017 IEEE Industrial and Commercial Power Systems Europe (EEEIC / I\&CPS Europe), Italy, Milan, 6-9 June 2017. Piscataway: IEEE, 2017, pp. 1308-1311. ISBN 978-1-5386-3918-4. doi:10.1109/EEEIC.2017.7977621.

\section{Scientific paper related to Chapter 3}

4. Petričenko, L., Broka, Z., Sauhats, A. Impact of Smart Electric Thermal Storage on Distribution Grid. In: 2017 IEEE International Conference on Environment and Electrical Engineering and 2017 IEEE Industrial and Commercial Power Systems Europe (EEEIC / I\&CPS Europe), Italy, Milan, 6-9 June 2017. Piscataway, NJ: IEEE, 2017, pp. 1330-1335. ISBN 978-1-5386-3918-4. doi:10.1109/EEEIC.2017.7977625.

\section{Scientific papers related to Chapter 4}

5. Broka, Z., Baltputnis, K., Sauhats, A., Sadoviča, L., Junghāns, G. Stochastic Model for Profitability Evaluation of Demand Response by Electric Thermal Storage. In: 2018 IEEE 59th International Scientific Conference on Power and Electrical Engineering of Riga Technical University (RTUCON 2018), Latvia, Riga, 12-14 November 2018. Piscataway, NJ: IEEE, 2018, pp. 449-454. ISBN 978-1-5386-69044. e-ISBN 978-1-5386-6903-7. doi:10.1109/RTUCON.2018.8659837.

6. Sadoviča, L., Junghāns, G., Sauhats, A., Broka, Z., Baltputnis, K., Lavrinovičs, V. Case Study - Assessing Economic Potential for Demand Response in Baltic Balancing Market. In: 2018 IEEE 59th International Scientific Conference on Power and 
Electrical Engineering of Riga Technical University (RTUCON 2018), Latvia, Riga, 12-14 November 2018. Piscataway, NJ: IEEE, 2018, pp. 257-261. ISBN 978-1-53866904-4. e-ISBN 978-1-5386-6903-7. doi:10.1109/RTUCON.2018.8659901.

7. Baltputnis, K., Broka, Z., Sauhats, A. Influence of Flexibility Modeling Parameters on Residential-Scale Demand Response Assessment. In: 2019 IEEE Milan PowerTech, Italy, Milan, 23-27 June 2019. Piscataway: IEEE, 2019, pp. 2053-2058. ISBN 978-1-53864723-3. e-ISBN 978-1-5386-4722-6. doi:10.1109/PTC.2019.8810947.

8. Baltputnis, K., Broka, Z., Sauhats, A. Analysis of the Potential Benefits from Participation in Explicit and Implicit Demand Response. In: 2019 54th International Universities Power Engineering Conference (UPEC 2019), Romania, Bucharest, 3-6 September 2019. Piscataway: IEEE, 2019, pp. 72-76. ISBN 978-1-7281-3350-8. eISBN 978-1-7281-3349-2. doi:10.1109/UPEC.2019.8893589.

Research results included in the Doctoral Thesis have been discussed at six international scientific conferences.

1. $57^{\text {th }}$ International Scientific Conference on Power and Electrical Engineering of Riga Technical University (RTUCON 2016) in Latvia, Riga on October 13-14, 2016.

2. $17^{\text {th }}$ IEEE International Conference on Environment and Electrical Engineering $\& 1^{\text {st }}$ IEEE Industrial and Commercial Power Systems Europe (EEEIC / I\&CPS Europe) in Italy, Milan on June 6-9, 2017.

3. 15th International Conference on the European Energy Market (EEM 2018) in Poland, Lodz on June 27-29, 2018.

4. $59^{\text {th }}$ IEEE International Scientific Conference on Power and Electrical Engineering of Riga Technical University (RTUCON 2018) in Latvia, Riga on November 12-14, 2018 .

5. $13^{\text {th }}$ IEEE PowerTech in Italy, Milan on June 23-27, 2019.

6. $54^{\text {th }}$ International Universities Power Engineering Conference (UPEC 2019) in Romania, Bucharest on September 3-6, 2019.

Selected additional peer-reviewed scientific papers developed during the Doctoral Studies but not included in the Thesis are listed below (all indexed in Scopus).

1. Sauhats, A., Coban, H., Baltputnis, K., Broka, Z., Petričenko, R., Varfolomejeva, R. Optimal Investment and Operational Planning of a Storage Power Plant. International Journal of Hydrogen Energy, 2016, Vol. 41, Iss. 29, pp. 12443-12453. ISSN 03603199. doi:10.1016/j.ijhydene.2016.03.078.

2. Baltputnis, K., Broka, Z., Sauhats, A., Petričenko, R. Short-Term Optimization of Storage Power Plant Operation under Market Conditions. In: 2016 IEEE 16th International Conference on Environment and Electrical Engineering (EEEIC 2016), Italy, Florence, 7-10 June 2016. Piscataway, NJ: IEEE, 2016, pp. 250-255. ISBN 978-1-5090-2321-9. doi:10.1109/EEEIC.2016.7555466.

3. Sauhats, A., Petričenko, R., Baltputnis, K., Broka, Z., Varfolomejeva, R. A MultiObjective Stochastic Approach to Hydroelectric Power Generation Scheduling. In: 2016 Power Systems Computation Conference, Italy, Genoa, 20-24 June 2016. Piscataway, 
NJ: IEEE, 2016, pp. 56-62. ISBN 978-1-4673-8151-2. doi:10.1109/PSCC.2016. 7540821.

4. Sauhats, A., Petričenko, R., Broka, Z., Baltputnis, K., Soboḷevskis, D. ANN-Based Forecasting of Hydropower Reservoir Inflow. In: 2016 57th International Scientific Conference on Power and Electrical Engineering of Riga Technical University (RTUCON 2016): Proceedings, Latvia, Riga, 13-14 October 2016. Piscataway, NJ: IEEE, 2016, pp. 267-272. ISBN 978-1-5090-3732-2. doi:10.1109/RTUCON.2016.7763129.

5. Baltputnis, K., Broka, Z., Sauhats, A. Assessing the Value of Subsidizing Large CHP Plants. In: 2018 15th International Conference on the European Energy Market (EEM 2018), Poland, Lodz, 27-29 June 2018. Piscataway: IEEE, 2018, pp. 488-492. ISBN 978-1-5386-1489-1. doi:10.1109/EEM.2018.8469816.

6. Petričenko, L,., Broka, Z., Sauhats, A., Bezrukovs, D. Cost-Benefit Analysis of Li-Ion Batteries in a Distribution Network. In: 2018 15th International Conference on the European Energy Market (EEM 2018), Poland, Lodz, 27-29 June 2018. Piscataway, NJ: IEEE, 2018, pp. 1-5. ISBN 978-1-5386-1489-1. doi:10.1109/EEM.2018.8469782.

7. Broka, Z., Baltputnis, K. Handling of the Rebound Effect in Independent Aggregator Framework. 17th International Conference on the European Energy Market (EEM 2020), Sweden, Stockholm, 16-18 September 2020. Piscataway: IEEE (accepted).

\section{Structure of the Thesis}

The Doctoral Thesis is written in English. It is composed of an introduction, four main chapters, conclusions, and bibliography with 117 references. The Thesis, containing 84 figures, 21 tables, and $\mathbf{5}$ appendices, consists of $\mathbf{1 7 0}$ pages.

Chapter 1 proposes an optimisation procedure of the balancing process of the Baltic power system. This is both an economically and politically important topic for cost-reduction of power system regulation and increase of the energy independence of the three Baltic countries. To ensure a balanced power system operation, it is important the TSO has enough flexibility resources at hand. As such, demand-side flexibility has been generally admitted being an underused resource, especially in the common Baltic balancing market with sometimes lacking balancing reserve providers. Therefore, subsequent chapters are dedicated to employment of demand response sources and their cost-benefit assessment.

Smart electric thermal storage is selected as a potential demand-side flexibility resource. Chapter 2 describes the technology and modelling approach employed to estimate the heating demand of buildings with a data-driven black-box approach. The derived consumption of DR-enabled electric heating devices is then used for their value and impact estimation both at the distribution grid and power system scale in Chapter 3.

Finally, Chapter 4 presents methodology and a tool for a probabilistic economic assessment of DR provision from the end-user point of view with a focus on their participation in the balancing market. The tool informs the potential DR providers on their probable cash flows considering uncertainties related to electricity wholesale and balancing prices and also market demand for the balancing resources. Thus, it can facilitate the entrance of new balancing market participants and increase the overall flexibility of the Baltic power systems. 


\section{OPTIMAL ACTIVATION OF BALANCING RESERVES}

\subsection{Motivation and Background}

This chapter is focused on a software tool, AOF parameter search, developed in 2017 in preparation for the launch of the common Baltic balancing market established in 2018 by the Latvian, Lithuanian, and Estonian transmission system operators (TSOs) with the overarching objective to develop a common Nordic-Baltic balancing market for manually activated frequency restoration reserves (mFRR) [24]. It presents practical research based on a real-life case study of the Baltic power system for optimal activation of manual frequency restoration reserves.

The tool for determination of the activation volume and time schedule for balancing reserves was developed to facilitate the decision-making process of the transmission system operator in balancing of the power system within a coordinated balancing area. The study is important in light of the ongoing integration of balancing markets within the European Union (EU) and the subsequent need to develop an activation optimisation function. Recently, regular balancing needs of the Baltic countries were covered mostly by the neighbouring Russian power system. The motivation for this study was moving towards local regulation as much as possible for energy dependence related and economic reasons.

The Baltic power system has some distinct characteristics due to its synchronous operation with the Integrated/Unified Power System (IPS/UPS) of Russia and Belarus. The Russian power system provides primary power reserves for frequency regulation and secure system operation within the BRELL (Belarus, Russia, Estonia, Latvia, and Lithuania) ring [4]. As of 2018, the three Baltic TSOs have established a common Baltic balancing market within which the three countries are able to share balancing energy. However, the remaining not netted imbalance is settled by an Open Balance Provider (OBP) which provides balancing energy from the Russian power system via seven transmission lines. The not netted imbalance with the OBP is defined as the total Baltic area control error (ACE), or the overall system imbalance. It is calculated as the difference between the scheduled and the actual power flow each minute, integrated over the whole imbalance settlement period (ISP) to obtain the final $\mathrm{ACE}$ in MWh. Thus, the payment for the Baltic ACE covers the cost of the Russian frequency control service [25].

Formally, the three Baltic countries are required to keep their imbalance within certain limits ( $\pm 30 \mathrm{MWh} / \mathrm{h}$ for Estonia and Latvia each and $\pm 50 \mathrm{MWh} / \mathrm{h}$ for Lithuania [24]). In practice, until the end of 2017 minor imbalances were handled by the imports from Russia on a regular basis while local activations were used to cover larger imbalances on comparatively rare occasions. As a result, the ACE energy constituted a major part of the total Baltic balancing energy and contributed a significant share of balancing costs in the Baltic markets (e.g., some $40 \%$ of total balancing costs in Latvia in 2014 [25]). Handling ACE with energy from the Russian power system is costly due to the specific pricing policy employed by the OBP: a low sell price fixed at $5 € / \mathrm{MWh}$ and a high buy price which may exceed $100 € / \mathrm{MWh}$ (data of 2015) [25]. For context, the average day-ahead market electricity price in the three Nord Pool bidding areas of the Baltic countries was 35.23€/MWh in 2016. 
The aforementioned considerations along with the political decision to cease synchronous operation with the IPS/UPS by 2025 [26] encouraged the Baltic TSOs to develop a Baltic balancing IT system with the primary function to ensure sustainable physical cross-border balancing. This system facilitates sharing balancing energy among the three countries with the aim to increase reliance on mFRR provided by local producers, the bids of which are included in the Baltic common merit order list (CMOL). It is expected to reduce the overall balancing costs incurred by the three Baltic TSOs while contributing to the energy independence of Latvia, Estonia, and Lithuania.

One of the building blocks of the common balancing system is the Activation Optimisation Function (AOF). As stipulated in the guidelines [27] developed by ENTSO-E, the AOF determines the most efficient activation of the incoming balancing request while respecting some capacity and operational restrictions. The Baltic TSOs intend to implement the AOF as an automatic algorithm the main inputs to which are the available bids from the CMOL (considering transmission constraints) and activation volume proposal [24], the latter being the focus of this study. Specifically, it implies an algorithm for determination of optimal activation volume of balancing reserves along with a time schedule based on the historic ACE data with minute resolution and the current ACE forecast. It is meant to support the decisionmaking by the dispatch operator of the transmission system, which thus serves as the first step towards building a fully automatic system for the activation of balancing reserves.

As of now, the ordering of the balancing energy is left solely to the dispatch operator with a very short timeframe for decision-making. Combining the time restriction with the large number of variable and uncertain parameters of the power system, it stands to reason that an automated tool should provide operational advantages.

\subsection{Methodology}

Within this study, we developed a software tool for deriving optimal activation parameters of mFRR for balancing of the Baltic power system. The main objective of the algorithm implemented is to identify close to optimal regulation parameters and to evaluate the performance of balancing operations carried out in accordance with these parameters. The optimisation problem is formulated and solved in MATLAB to take advantage of its data processing abilities and solvers. MS Excel is used for input and output due to its user-friendly interface.

Development of the AOF parameter search tool took place in 2017. It was commissioned by the Latvian TSO, "Augstsprieguma tikkls" AS, within the research contract work "Development of mathematical models for an economic assessment of demand-side flexibility resources and activation optimisation of balancing reserves". The scope of the tool is the activation of balancing reserves (namely, mFRR) provided within the common Baltic balancing market to minimise the ACE covered by OBP (Fig. 1.1).

The core of $A O F$ parameter search is an algorithm for activation volume and time suggestion. It is implemented as a stand-alone application to inform the dispatch operator whether, at a certain point within an ISP, balancing activation must be ordered and, if so, in 
which direction and to what extent. The algorithm receives as its input minutely data of the Baltic area control error (ACE) forecast along with the final ACE at the end of each ISP (currently, an hour). Then, an optimisation procedure is employed (Fig. 1.2) to determine the most efficient balancing schedule based on the historic ACE data.

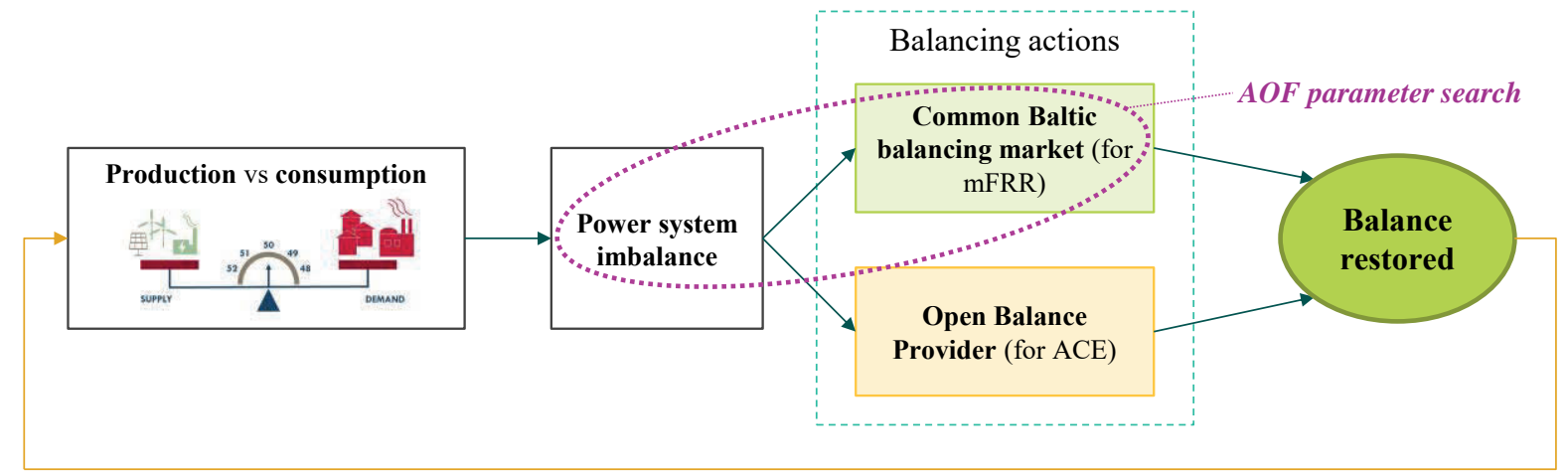

Fig. 1.1. The role of $A O F$ parameter search tool within the Baltic balancing process.

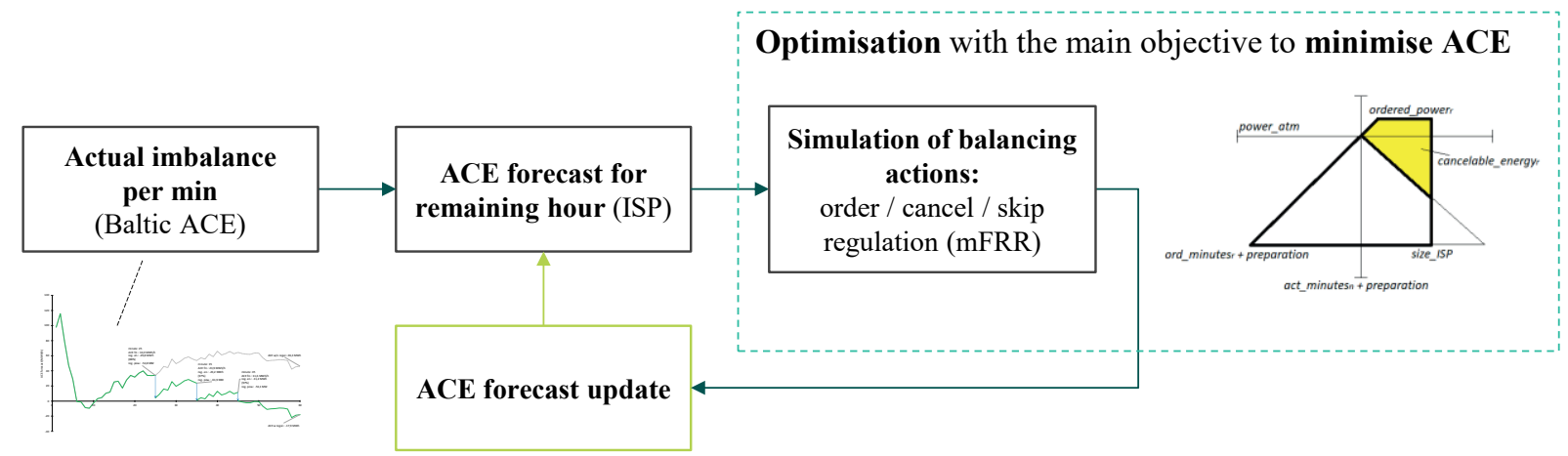

Fig. 1.2. A simplified illustration of $A O F$ parameter search operation.

The balancing energy is dispatched based on three distinct sets of parameters:

- time of activation (minutes from the beginning of each ISP);

- percentage of the ACE forecast to be regulated against;

- ignorance level, which is the threshold the ACE forecast must meet for regulation to be activated.

\subsubsection{Objective Function}

To calculate the value of the objective function, the tool iterates through the imbalance settlement periods (ISPs - hours in the current implementation) of the ACE data provided and simulates the process of regulation activation within each ISP with a set of given parameters. For multi-objective optimisation, we employ the weighted sum method to scalarise a set of objectives into a single-objective function, which is the subject of minimisation. Its value is made up of several metrics, the most important of which usually is the sum of the absolute values of ACE at the end of each ISP. The other two metrics considered in the software tool are the sum of the provided balancing energy and the sum of the balancing power orders during each ISP. The combination of these metrics is made possible by imposing userselected weight coefficients to each criterion of the problem statement. Their primary 
purpose is to set the importance of each of the components within the objective function, but they also aid in ensuring that the various components can agree dimensionally. Thus, the objective function can be expressed as

$$
w_{1 \mathrm{a}} \sum_{I S P=1}^{I S P S} A C E_{\mathrm{pos}}^{I S P}+w_{1 \mathrm{~b}} \sum_{I S P=1}^{I S P s}\left|A C E_{\text {neg }}^{I S P}\right|+w_{2} \sum_{I S P=1}^{I S P S}\left|E_{\text {reg.suppl. }}^{I S P}\right|+w_{3} \sum_{I S P=1}^{I S P S}\left|P_{\text {reg. ord. }}^{I S P}\right| \rightarrow \mathrm{min},
$$

where $w_{1 \mathrm{a}}, w_{1 \mathrm{~b}}, w_{2}, w_{3}$ - weight coefficients for the various criteria of the problem statement; $A C E_{\text {pos }}^{I S P}$ - positive ACE, or net balancing energy exported to the Russian power system during the ISP, MWh/h; $A C E_{\text {neg }}^{I S P}$ - negative ACE, or net balancing energy imported from the Russian power system during the ISP, MWh/h;

$E_{\text {reg.suppl. }}^{I S P}-$ total provided balancing energy during the ISP, MWh;

$P_{\text {reg.ord. }}^{\mathrm{ISP}}-$ sum of the ordered regulation power during the ISP, MW;

$I S P S$ - number of ISPs in the training dataset.

The weight coefficients can be adjusted by the user depending on their priorities. In our case studies, the primary goal was to minimise the ACE at the end of each ISP, while also trying to efficiently reduce the amount of balancing energy used and the ordered regulation power.

Optimisation variables comprise a set of parameters a dispatch operator would use for the actual balancing actions, namely: (1) time of activation (minutes from the beginning of each ISP); (2) percentage of the ACE forecast to be regulated against; (3) ignorance level which is the threshold the ACE forecast must meet for regulation to be activated. The constraints for these variables are set by the user. Additionally, the user selects the maximum number of activations per hour (1...5), the preparation time for activation of reserves and the ramp rate. All these settings serve as constraints during the optimisation and are used for simulating the regulation actions.

Given that the objective function is very complicated (it includes passing the entirety of the training dataset through regulation activation logical instructions including both ordering of regulating power and its partial or full cancellation taking into account ramping), traditional gradient-based solvers cannot be used. Instead, more versatile solvers, e.g., MATLAB patternsearch, should be employed. Another issue caused by the complexity of the objective function is the risk of stopping in local minima, which can be partially alleviated by implementing a multi-start call to the solver (i.e., beginning the search at different initial points). The greater the number of calls to the solver, the greater the chance of finding a better solution at the cost of higher computational time. Nevertheless, absolute certainty of obtaining the global minimum cannot be established by definition, hence a precaution in the terminology used - hereinafter the term optimum solution refers to the output of the solver and generally describes the best solution the solver was able to find under the particular circumstances and time allocated to it. 


\subsubsection{Regulation Simulation Logic}

To simulate the regulation actions, we assume that three distinct decisions can be made at each decision point (time of activation): order regulation; request a change (incl. cancellation) of a previously ordered regulation; do nothing. The set of instructions which carries out the task of simulating regulations within the inner loop of the objective function calculation has a fairly complex structure. It takes into account factors like preparation time (from making the decision to order/change regulation to the beginning of its implementation), ramping rate (from one power state to another), and feasibility of the necessary regulation energy to actually be delivered in the remaining time within the ISP (this, in combination with the ramp rate, also defines the ceiling of power that can be ordered at a given activation time).

The decision to call for regulation activation is made if at a given activation minute the ACE forecast meets or exceeds the ignorance level. The ACE forecast is updated correspondingly. The decision to cancel a previous regulation also requires a violation of the ignorance level, but additionally, the sign of the ACE forecast needs to have changed. The cancellation, in this case, allows avoiding a situation where two activations in opposite directions are online at the same time, thus minimising the amount of regulation energy which has ultimately been wasted by shifting the ACE in the wrong direction, requiring additional regulation to alleviate this.

\subsection{Results and Discussion}

To obtain (close to) optimum mFRR activation parameters, the optimisation procedure was applied to historical data of the year 2016 provided by the TSO which was divided into training and testing subsets. Data series of the ACE forecast and the actual ACE with minute resolution was split into three-month periods in an attempt to capture seasonal differences in data. This approach also reflects the intended use of the algorithm by the Baltic TSOs, namely, its application on historic data of one or a few months to obtain activation parameters which are then used to assist the operators in balancing the power system for upcoming periods (e.g., one or a few months). Regulation parameters were optimised on the training dataset comprising the first $2 / 3$ of the whole preprocessed set. To test the performance of the optimised balancing schedule, the estimated parameters were applied on the testing dataset (i.e., the remaining 1/3) to simulate all activities of regulation as performed by the TSO. Consequently, the results presented show the performance of regulation only for the testing set and allow us to evaluate the generalisation ability of the optimisation procedure.

The optimised activation parameters and resulting ACE for one of the three-month data sets (July-September 2016) are shown in Table 1.1. The resulting ACE after simulating the balancing activities according to the optimised schedule for the same period is also shown in Fig. 1.3. The ACE is noticeably reduced (up to 4.9 times) from $37.95 \mathbf{M W h} / \mathbf{h}$ before any regulation to 7.71-12.50 $\mathrm{MWh} / \mathrm{h}$. 
Table 1.1

Optimised Regulation Parameters and Resulting Imbalance

\begin{tabular}{|c|c|c|c|c|c|c|c|}
\hline \multicolumn{8}{|l|}{ Optimized reg. parameters } \\
\hline \multicolumn{3}{|c|}{ max number of activations } & 1 & 2 & 3 & 4 & 5 \\
\hline \multicolumn{3}{|l|}{ activation minutes } & 35 & $23 ; 45$ & $22 ; 34 ; 45$ & $15 ; 25 ; 35 ; 45$ & $5 ; 15 ; 25 ; 35 ; 45$ \\
\hline $\begin{array}{l}\text { volume of activation } \\
\text { relat. to ACE forecast }\end{array}$ & & 90.5 & $75.4 ; 97.4$ & $\begin{array}{l}65.9 ; 81.9 \\
98.5\end{array}$ & $\begin{array}{l}50.1 ; 50.7 \\
80.6 ; 93.7\end{array}$ & $\begin{array}{c}31.1 ; 31.1 ; \\
31.1 ; 76.7 ; 94.3\end{array}$ \\
\hline ignorance threshold & \multicolumn{2}{|l|}{$\mathrm{MWh}$} & 10.0 & $22.1 ; 10.0$ & $\begin{array}{c}33.0 ; 27.5 \\
10.0\end{array}$ & $\begin{array}{c}192.0 ; 107.0 \\
31.0 ; 10.0\end{array}$ & $\begin{array}{c}182.0 ; 137.5 ; \\
81.8 ; 33.0 ; 10.0\end{array}$ \\
\hline \multicolumn{2}{|l|}{ Imbalance indicators } & $\begin{array}{l}\text { W/o local } \\
\text { reg. }\end{array}$ & \multicolumn{5}{|c|}{ After local regulation with optimized parameters } \\
\hline Average $|\mathbf{A C E}|$ & $\mathrm{MWh} / \mathrm{h}$ & 37.95 & 12.50 & 9.04 & 7.71 & 7.71 & 7.78 \\
\hline Average ACE & $\mathrm{MWh} / \mathrm{h}$ & 21.85 & 4.42 & 3.63 & 2.47 & 2.73 & 2.55 \\
\hline Sum $|\mathrm{ACE}|$ & MWh & 19315 & 6364 & 4601 & 3924 & 3923 & 3961 \\
\hline Sum pos. ACE & MWh & 15218 & 4308 & 3224 & 2590 & 2657 & 2630 \\
\hline Sum neg. ACE & MWh & -4097 & -2056 & -1377 & -1335 & -1266 & -1331 \\
\hline $\begin{array}{l}\mid \mathrm{ACE} \text { forecast error } \mid \\
\text { (a) last activ. }\end{array}$ & \multicolumn{2}{|l|}{$\mathrm{MWh} / \mathrm{h}$} & 10.67 & 6.34 & 6.34 & 6.34 & 6.34 \\
\hline Balancing energy suppl. & GWh & & 16.419 & 19.116 & 19.394 & 17.527 & 17.605 \\
\hline up-regulation & GWh & & 3.775 & 4.921 & 4.764 & 3.899 & 3.891 \\
\hline down-regulation & GWh & & 12.644 & 14.195 & 14.630 & 13.629 & 13.714 \\
\hline
\end{tabular}

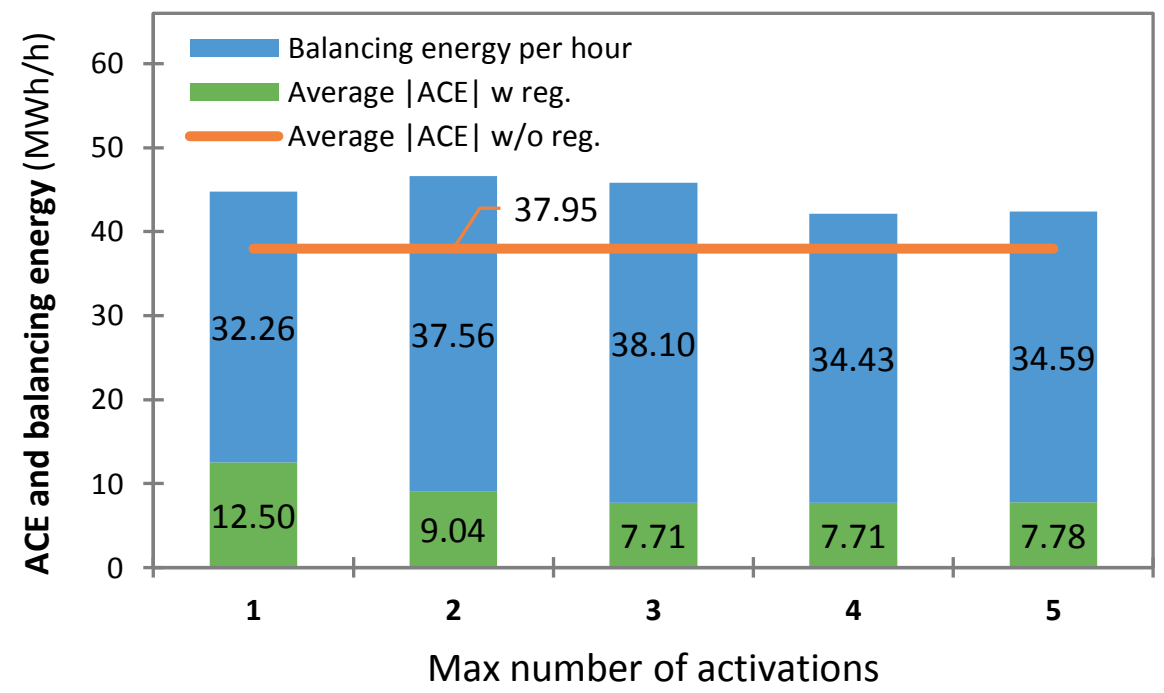

Fig. 1.3. Average $|\mathrm{ACE}| \mathrm{w} / \mathrm{o}$ and $\mathrm{w}$ reg. and provided balancing energy.

The stacked chart in Fig. 1.3 allows to assess the efficiency of regulation in terms of the provided balancing energy and improvement of the ACE. The sum of the ACE after regulation and provided balancing energy is always more than the ACE without any regulation because of the ACE uncertainty which sometimes causes redundant orders. During the specific period, the most efficient regulation happens when the max number of activations is $4-5$. Then, cancellation is needed for only $1.4-1.7 \%$ of the ordered energy respectively. Also, less balancing energy is used to reduce the ACE compared to cases with 2-3 activations. This is due to more gradual and cautious regulation which is possible with a larger number of activations within the ISP.

It is important to note that the average absolute error of the ACE forecast at the minute 45 was $6.34 \mathrm{MWh} / \mathrm{h}$ in July-September 2016 (Table 1.1). This is very close to the lowest 
average ACE value achieved $(7.71 \mathrm{MWh} / \mathrm{h})$ which again demonstrates the efficiency of the proposed activation parameters when applied on the testing set.

In all the cases but with only 1 activation, the last selected activation minute is 45 , which is the upper bound imposed during the optimization. This is due to the initially highly uncertain nature of the ACE forecast, the accuracy of which significantly increases towards the end of each ISP (Fig. 1.4). Since premature activation can lead to redundant orders for regulation and the subsequent cancellation of regulations that happen to be in the opposite direction, the algorithm evidently tends to postpone activations as long as possible.

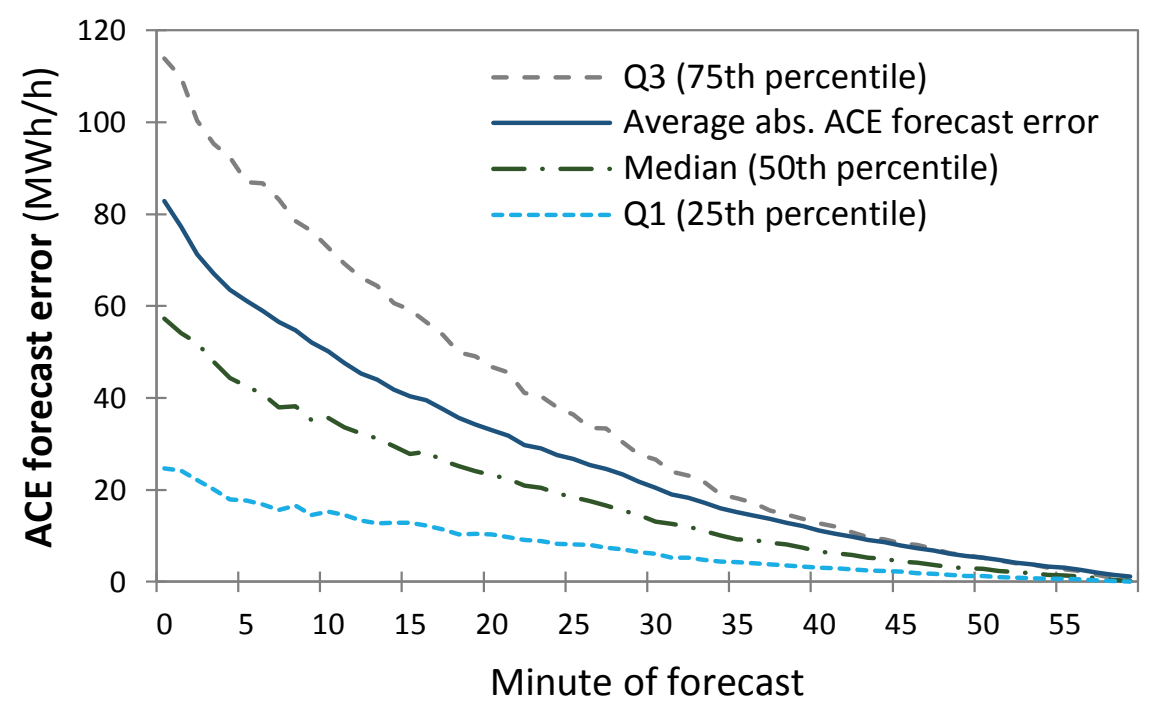

Fig. 1.4. Statistics of the absolute ACE forecast error depending on the minute of forecasting within the ISP of one hour.

Fig. 1.5 presents frequency distribution of the hourly ACE without and with regulation applied to the testing subset of July-September 2016 dataset (509 hours in total). The ACE without regulation (blue bars) is moderately skewed to the right with an average value of $+21.9 \mathrm{MWh} / \mathrm{h}$. This can be explained by the behaviour of balance responsible parties (BRP) who tend to prefer long rather than short positions because the potential financial risk for 'short' prices is inclined to be more extreme than for 'long' prices [25]. As a result, the Baltic countries in general sell more energy to the OBP than they buy. After applying the optimized regulation parameters to the test set of July-September 2016, the average ACE decreases from $+21.9 \mathrm{MWh} / \mathrm{h}$ to $+2.5 \mathrm{MWh} / \mathrm{h}$ (Fig. 1.5, orange bars). Thus, the noticeable positive bias of the ACE is almost eliminated. This clearly demonstrates not only a good performance of regulation with the optimized parameters but also the generalisability of the obtained parameters when applied to the testing data. 


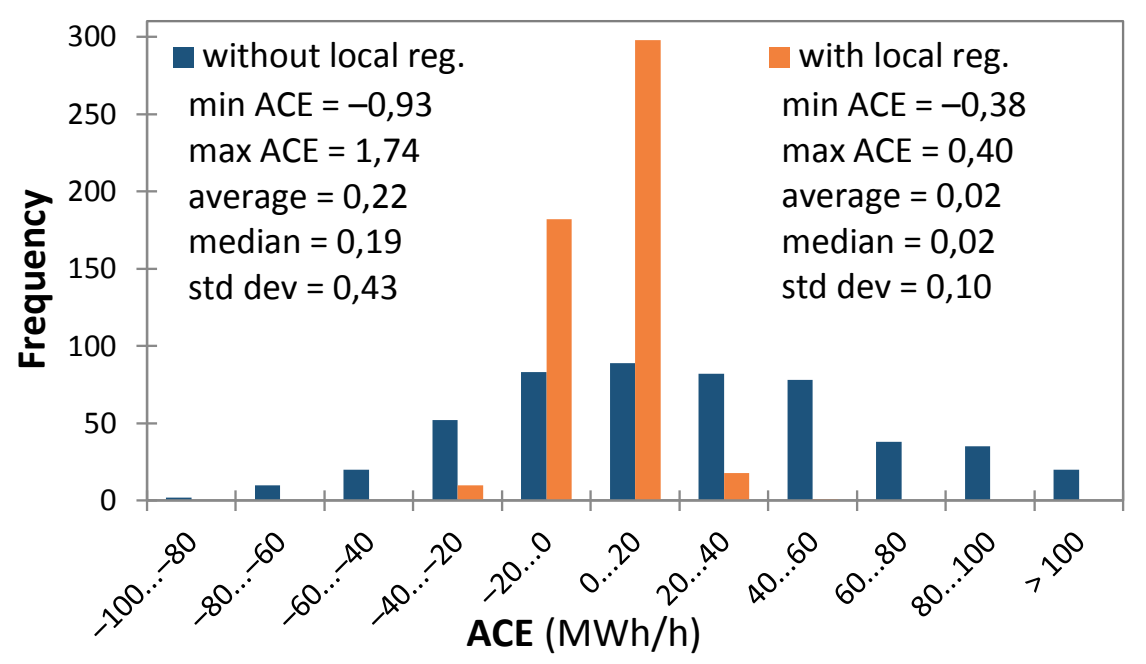

Fig. 1.5. ACE histogram w/o local reg. and w reg. (3 max activations).

\subsection{Summary}

The numerical simulations of balancing activations based on the parameters optimised using historical time series affirmed the generalisability of the results, since in most of the cases the average absolute ACE was close to the forecast error. Additionally, this confirms improved ACE forecasting techniques to be a promising avenue for further research as any enhancements there can be expected to notably improve the efficiency of balancing operations. Furthermore, as currently the balancing parameter optimisation tool tends to postpone regulation to later part of the ISP when forecasts are more accurate, perfected early prediction abilities would allow for more even balancing operations throughout the ISP.

For the dataset considered in this study, 4 and 5 were identified as the maximum number of activations during the ISP equal to one hour that can provide the most efficient balancing. While the case with 3 maximum activations did provide a small overall ACE, the aforementioned cases were superior in terms of the utilised balancing energy and estimated cost.

While our tool can still be expanded to incorporate the merit order of balancing bids, the initial simplified economic calculations already point to noticeable financial gains from a more active local balancing in the Baltic power system and decreased reliance on regulation from the Russian power system, especially with the OBP's balancing energy pricing policy in place at the time of the study.

Even disregarding the financial aspects, the evolution of the common Baltic balancing market is well underway after its launch at the beginning of 2018. Similar trends are ongoing throughout Europe as the TSOs need to adapt the recently established European Commission guidelines on electricity balancing and devise their AOFs for more efficient power system balancing. Thus, this study proves to be of significant relevance in the light of the changing balancing market landscape in Europe. The initial results of this study have informed some of the decisions of the Baltic TSOs in the development of their common balancing market. Moreover, this is also important as the Baltic countries strive to desynchronise from the IPS/UPS by 2025 . 


\section{MODELLING OF DR-ENABLED ELECTRIC HEATING}

\subsection{Motivation and Background}

Dissemination of intermittent renewable energy sources (RES) such as wind, wave, and solar power presents new challenges for the power systems. To reduce the curtailment of renewables and efficiently accommodate the distributed and variable RES across the power system, energy storage has become a necessity. Various forms of energy storage include mechanical energy storage (hydropower, compressed air, flywheel), electrochemical batteries, power to gas storage, electric and magnetic energy storage (capacitors and supercapacitors, superconducting materials), and thermal energy storage.

While there are mature and long-known technologies for large-scale energy storage such as pumped-storage hydropower, which is the most used storage option in the power sector worldwide, many efforts are devoted to the development of small-scale energy storage primarily for use in the residential sector. One of such technologies is smart electric thermal storage with household appliances for space heating and hot water heating [28]. It is a sensible heat storage system [29] which consumes electricity and is able to store it in the form of thermal energy for a long time to be used later just when it is needed. Thus, the power demand of the heating system is decoupled from the time of thermal energy end-use by the domestic customer.

Electric thermal storage heaters have been in use for decades especially in countries where two-tariff electricity pricing is applied to households. Conventional thermal storage heaters had limited controllability due to relatively low heat retention rate. However, for the newest generation of smart electric thermal storage (SETS) system, the heat retention rate is significantly improved, and the recent advances of information and communication technologies have allowed a significant technological development of the storage heaters. SETS devices are now equipped with smart control at the aggregate electric power system level while ensuring that individual household space and water heating end-use requirements are maintained [28]. It allows to decouple the electricity demand from the expected heat output and deliver electricity to the SETS virtually at any time while consuming the heat at any other time when it is needed. Consequently, the whole electricity supply chain, including generation, transmission, distribution, and consumption, can potentially benefit from SETS.

SETS can provide overall societal benefits such as cost savings to the customers and RES curtailment reduction, whereas the aggregated load can offer a number of services to the power system such as demand shifting and demand response, ancillary services (frequency response, reserves provision), congestion management, and deferral of capital investments into the network.

While the SETS technology and appliances are in place already [28], the power systems are not yet in a position to integrate them, and there are various ongoing studies on how to facilitate this process. One of the problems to be solved includes co-optimisation of the electricity system scheduling together with requirements of the electric heating demand [29]. The modelling and optimisation environment for electrical power systems should 
endogenously represent the local small-scale thermal storage devices, including their technical characteristics and thermal energy end-use requirements.

To assess the potential cost savings to the customers when using SETS with dynamic pricing under conditions of a liberalised electricity market, the variable electricity prices need to be considered with appropriate temporal resolution (e.g., hourly resolution for the Nord Pool day-ahead market prices). Consequently, thermal energy end-use should also be modelled with an hourly resolution.

This section is focused on modelling the residential heating energy demand. We propose an approach based on physical experiments and virtual simulations to obtain the equivalent thermal characteristics of the building which can then be used for modelling the thermodynamics of the building under different weather conditions.

The approach presented here served as a basis for our further studies involving physical experiments in different buildings in Latvia to derive their thermal characteristics and heating energy requirements. The consumption of individual buildings can then be scaled to a national aggregate level. The aggregated electric load of local small-scale thermal storage will be integrated into the overall power system models to assess the impact of SETS on power system planning, unit commitment and dispatch of energy and reserves, distribution network congestion, etc. Main results from this impact assessment are presented in Chapter 3. Furthermore, the heat demand modelling results have been also used for cost-benefit assessment of demand response from SETS from the end-user point of view in Chapter 4.

The scientific work presented in Chapters 2 and 3 took place during 2015-2018 as part of the RealValue project, which received funding from the European Union's Horizon 2020 research and innovation programme under grant agreement No 646116.

\subsection{Methodology}

\subsubsection{Thermal Model Based on Electrical Analogy}

For modelling thermodynamics of buildings, $R C$-diagrams are often used based on electrical analogy where each element of the building can be represented with resistors and capacitors as lumped parameters [30]-[34]. Such thermal network models have advantages of simplicity, transparency and low computational effort [31]. Theoretically, the simplest network might consist of one resistance and one capacitor [35]. However, this is practically and physically unrealistic, therefore usually more elements are used. For example, [31]-[33] use second-order models that describe construction elements by three resistances and two capacitances. In [33], this reduced-order model is devised from a $20^{\text {th }}$-order model through nonlinear constrained optimisation and is given preference over an even simpler first-order model since the latter showed considerable performance differences from the high-order model, unlike the second-order model. This approach is further improved in [31] by using a multi-objective function search algorithm and reporting a large number of results for various construction elements. 
For this study, we devised a simplified thermal network model presented in Fig. 2.1 which is suitable for inverse modelling to obtain equivalent thermal parameters in a computationally efficient way. Resistances represent heat transfer by conduction, whereas capacitances stand for thermal mass which reflects the ability of a material or a combination of materials to store energy. The model is developed in MATLAB Simscape (Fig. 2.2) which enables creation of models of physical systems and simulation of their thermal performance using MATLAB Simulink.

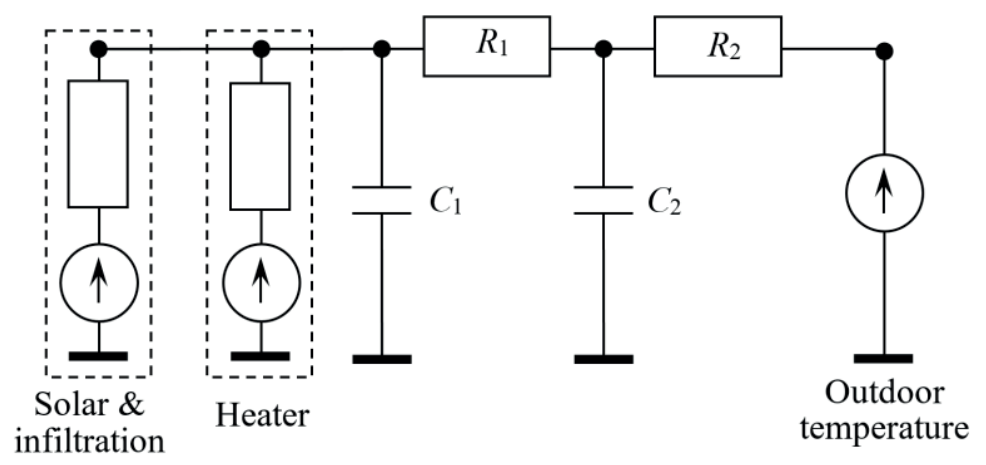

Fig. 2.1. Building thermal network used for inverse modelling.

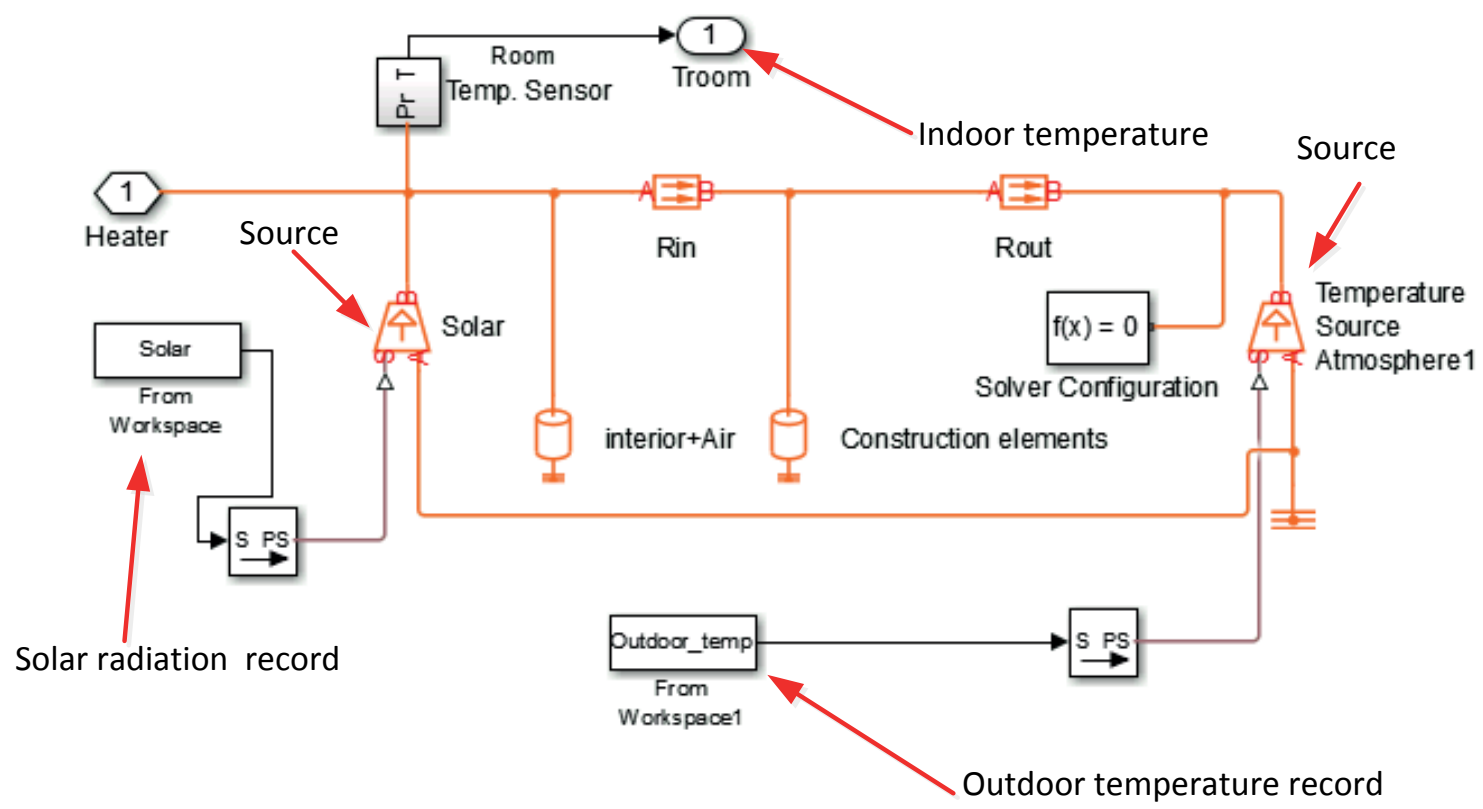

Fig. 2.2. Building thermal model in MATLAB Simscape.

\subsubsection{Model Parameter Estimation}

To obtain the equivalent thermal network parameters for each building of interest, first of all, model parameter identification was performed. Equivalent thermal parameters $R_{1}, R_{2}, C_{1}$, and $C_{2}$ (Fig. 2.1) were estimated according to the algorithm shown in Fig. 2.3. Model parameters were generated randomly employing Monte Carlo sampling and then applied to the simplified thermal network for simulation. The output of the model (energy consumption) was compared with measurements of virtual or physical experiments using mean square error 
as the error measure. The sampling was repeated for $100^{n}$ times, where $n=4$ is the number of unknown parameters. The parameters which provided the most accurate performance of the model were saved. This approach involves a partial enumeration with a high accuracy thanks to the Monte Carlo random sampling, which allows selecting a result close to the global minimum avoiding local minima. The model with its tuned parameters can then be used for building heating energy demand modelling at the individual and aggregate level.

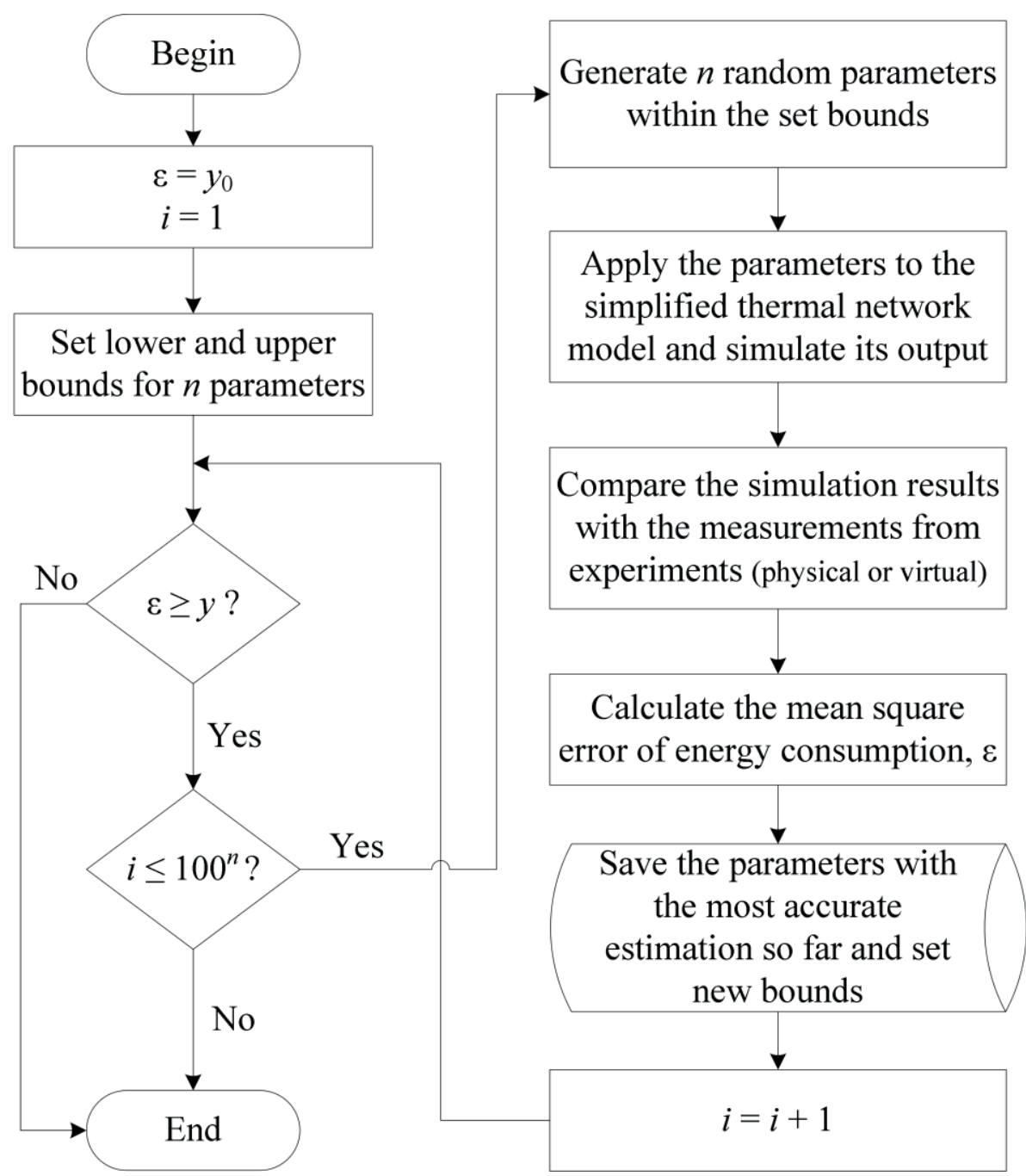

Fig. 2.3. Flowchart for parameter estimation of the thermal network.

The proposed building heat demand modelling approach was validated via virtual and physical experiments. Virtual experiments involved comparison of the proposed model simulation results to two more complex models, whereas physical experiments were carried out in a real residential house allowing to identify its thermal parameters to compare the building's actual (measured) and simulated thermal performance. 


\subsubsection{Simulation of Building Thermal Performance simulation}

Building models with the estimated equivalent thermal parameters were then used to simulate their thermal performance in MATLAB Simulink (Fig. 2.4). 'House Thermal Network' in Fig. 2.4 stands for the thermal model shown before in Fig. 2.1.

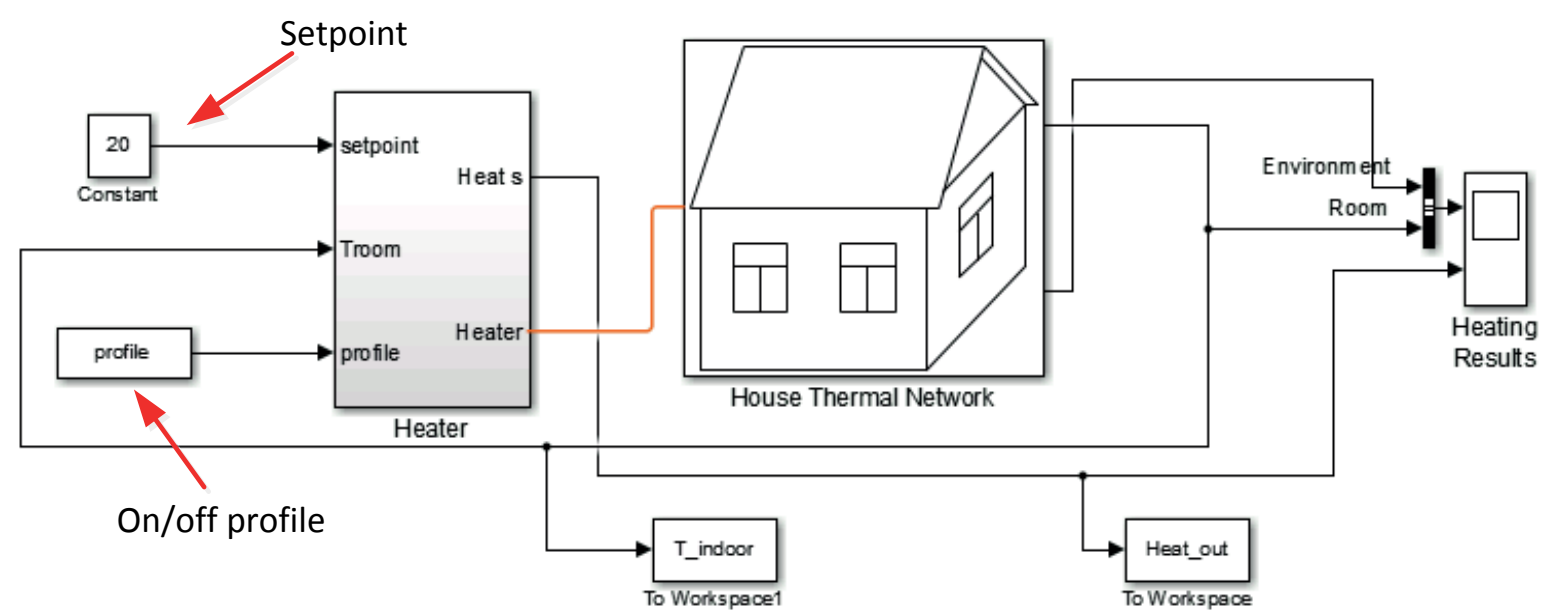

Fig. 2.4. Model for simulation of building thermal performance in MATLAB Simulink.

To simulate the thermal performance of each building, we input a heating schedule based on comfort requirements of the residents comprising a temperature setpoint and an hourly on/off profile reflecting the periods when heating is or is not required. This type of comfort control mimics the operation of SETS that were used for trials in Latvia within the RealValue project. For simulations, different comfort requirements were used based on the end-user type and building occupancy. The simulation can be run for any period of interest, e.g., 24 hours (one day) or 8760 hours (one year). The model simulation then outputs the space heating demand and the indoor temperature as hourly time series to be used in further modelling efforts.

\subsection{Results and Discussion}

Based on the methodology presented before, models for several buildings have been developed. The validated models were used to estimate the heating demand over a year using the hourly outdoor temperature and solar radiation. Fig. 2.5 shows the modelled room temperature and heat demand time series for a detached wooden house of $70 \mathrm{~m}^{2}$ in 2016 .

Given a setpoint of $20^{\circ} \mathrm{C}$ and 20-hour comfort profile daily, the simulated annual heat demand is $11.13 \mathrm{MWh}$ with an average of $159 \mathrm{kWh} / \mathrm{m}^{2}$. The highest heat demand occurs in January (hour 0-744) which coincides with the coldest weather of the year. During the hottest days in summer the room temperature often exceeds the setpoint of $20^{\circ} \mathrm{C}$, since the cooling system of the building is not being modelled. Conversely, we can also observe that additional heat is required a few times in summer when cold weather occurs. The developed model enables calculation of hourly heat demand time series with different comfort profiles and occupancy patterns. For example, the annual heat demand for the same building with $19{ }^{\circ} \mathrm{C}$ setpoint and 17-hour comfort profile is $10.28 \mathrm{MWh}$ ( $7.6 \%$ less than in the previous case). 

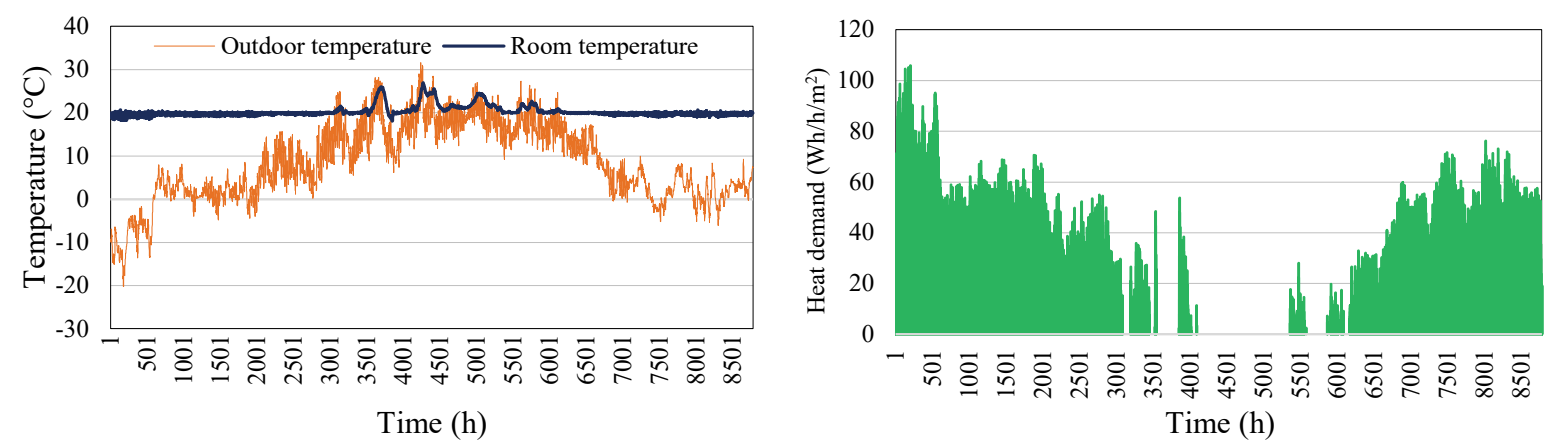

Fig. 2.5. Heat demand of a single-family wooden house.

Using the experimental data measured in different houses, it is possible to derive thermal characteristics for various types of buildings. Thus, we are able to calculate the heating demand of representative individual buildings and extrapolate it to a national scale to further assess the impact of a large amount of smart electric thermal storage appliances on the power system. The heat demand obtained from thermal modelling is then incorporated into distribution grid and power system models presented in Chapter 3 where the impact of largescale SETS deployment on the distribution grid and power system operation in Latvia is assessed. The heat demand is then translated into electricity consumption which forms an additional load, which is a supplement to the existing base load.

\subsection{Summary}

A simplified thermal network based on electrical analogy was developed using data on indoor and outdoor temperature, solar irradiation, and heat consumption. Equivalent thermal parameters of the simplified model were obtained through inverse black-box modelling. For validation of the method, virtual and physical experiments were conducted, and performance of the simplified thermal network model was compared to two more complex RC models and measurements in an existing building. It was concluded that the simplified and computationally efficient model was able to replicate the thermal dynamics of complex models and building with sufficient accuracy. Thus, the derived heat demand can be used for further modelling of SETS impact on different power system operation aspects. The selected inverse modelling method is also motivated by the limited data availability on the Latvian building stock and its future forecasts and to benefit from real-world operational data obtained through the physical trials of SETS in Latvia within the RealValue project.

Consequently, the developed building models are used to estimate the hourly heat demand over a year depending on the outdoor temperature and solar irradiation for different types of buildings. Based on the type of building or end-user, different occupancy profiles and comfort settings (i.e. heating schedule and setpoints) are assigned to it and accounted for when estimating the heat demand, thus capturing different consumption patterns of thermal energy. 


\section{VALUE ESTIMATION OF SETS AS A DR-ENABLED RESOURCE}

\subsection{Motivation and Background}

While smart electric thermal storage (SETS), being an advanced and DR-enabled technology, could potentially bring significant advantages to the power system, it does not come without a cost, such as an increase of electric consumption (if SETS is to replace other types of heating sources) and changes of the load curve possibly contributing to grid congestion risks and increase of grid losses, increased bills for electricity, etc. It has been identified that a major challenge for flexible demand response is the lack of understanding of its potential benefits due to a lack of methodologies for the quantification of costs and benefits [36]. Therefore, this section presents the methodology we developed for an overall cost-benefit assessment of SETS impact on the power system operation until 2050. For the study, we use various EU and national-level future scenarios and updated models simulating different aspects of power system operation developed in the Institute of Power Engineering of RTU to assess the benefits SETS might bring from two perspectives, the power system at large and, on a smaller scale, a representative distribution feeder network which also enables capturing cost-saving benefits individual households might experience. This study was performed during 2015-2018 within the RealValue project and is based on the Latvian power system, including the electricity market, characteristics at that time. The results of the study served as input to several RealValue deliverables approved by the European Commission.

The analysis of SETS impact is implemented by envisioning partial electrification of heating supply in Latvia at various penetration levels. In the baseline, the heating electrification is carried out with direct resistive heating (DRH) devices having no energy storage abilities or smart control whatsoever. The study is conducted for years 2020, 2030 and 2050, although most of the focus is on 2030 since 2020 is too soon for any major breakthroughs in SETS adoption in Latvia to actually take place, whereas 2050 is too far in the future for the conclusions drawn to have high reliability.

The approach chosen for the impact assessment of SETS on the Latvian power system is motivated by the heating technologies currently used in the residential sector and the data that is available for heat demand modelling at the national scale. As indicated in [37], $69 \%$ of the Latvian population or $64 \%$ of all dwellings are served by central heating (it comprises mainly district heating in cities and some local central heating). The second most common type of heating is stove or fireplace heating used by $29 \%$ of the population and in $32 \%$ of all dwellings. These results closely correlate with the share of multi-apartment buildings and detached houses in the housing stock since district heating is the most popular type of heating in apartments, but stoves and fireplaces are mostly used in rural individual houses. Unfortunately, central heating is not further detailed in the available statistics and thus it includes both district heating and local central heating. Local central heating, in general, can be used in detached buildings and multi-apartment buildings alike. Only 3-4\% of dwellings 
use other types of heating (including electric) as the main heating source. The Central Statistical Bureau of Latvia does not provide a further breakdown for the other types; however, it can be concluded that the share of electric heating in Latvia is negligible. Moreover, electric thermal storage heating is not used almost at all. Nevertheless, $26.7 \%$ of dwellings use electric water heaters. As a result, for the purposes of assessment of SETS impact on the Latvian power system, SETS equipment for space heating is modelled as an additional electric load rather than a replacement of existing electric heating appliances. The objective is to estimate the impact of partial heating electrification on the Latvian power system in various scenarios and by different technologies (e.g., SETS and direct resistive heaters) for the selected years of study (2020, 2030 and 2050).

Regarding data availability for heat demand modelling, there is a limited amount of information on detailed thermal characteristics of buildings in Latvia and their classification based on the actual building thermal performance that could be used for devising accurate building archetypes and upscaling them to the national level. Besides, it was found that there are no forecasts available on the future housing stock. Given the unavailability of data to be used for the secondary research and since carrying out such study as a primary research effort within the RealValue project was out of scope for the Latvian case study, a data-driven approach was selected for thermal modelling of buildings as already introduced in Chapter 2 . Moreover, the choice of methodology was also motivated by the physical demonstration of SETS in 50 trial objects in Latvia managed by RTU during which it was planned to obtain detailed operational data of the installed heating equipment via the aggregator employed for the RealValue trials. The available data from the aggregator includes comfort requirements of end-users, heat consumption, room temperature, etc. The derived heat demand was then translated into electric consumption of SETS to be used as input for power system modelling.

\subsection{Modelling of SETS Impact on the Distribution Grid}

The Latvian distribution system is operated almost exclusively by a single operator,

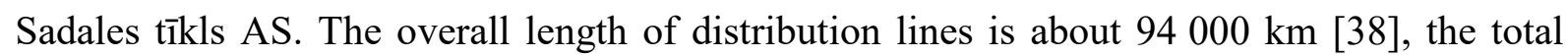
amount of energy demand in 2016 was $6465 \mathrm{GWh}$, of which about $25 \%$ was consumed by residential customers and the rest by the commercial and industrial sectors. Distribution losses amounted to $4.6 \%$ in 2016 [38]. The total capacity of the Latvian distribution network is 5892 MVA. These statistics allow evaluating the overall utilisation efficiency of the grid which is equal to $13 \%$, indicating a relatively low usage. The grid is widely spread across the country and highly branched with a relatively large number of distant customers that contribute to low overall usage efficiency. However, due to the socio-economic trends, the largest share of the load is concentrated in cities, and urbanisation is continuing. Lately, a lot of efforts and investments have been devoted to improving reliability by reconstructing old lines and substations and enforcing automation of the network. The national roll-out of smart meters, which has been ongoing since 2014, is to be completed by 2022 . It is carried out by the distribution system operator (DSO) that installs the meters for all customers free of charge. 


\subsubsection{Approach Overview}

Given that electric heating is not currently widespread in Latvia [37], for distribution modelling to assess the impacts of SETS, partial electrification of heating is assumed and the power flow study is carried out based on the existing electric load (base load) supplemented by the additional heating load. The modelled impact of smart electric thermal storage (SETS) devices is compared to that of direct resistive heaters. This enables assessing the implications of heating electrification in general and that of the studied technologies in particular. As another possibly competitive technology that can provide storage residential electrochemical batteries along with direct resistive heaters were studied in the Doctoral Thesis.

Since heat demand accounts for a large share of overall energy requirements in Latvia (it being located in the Northern part of Europe and having a long heating season of about 200 days), it is important to evaluate how heating electrification might impact the power system, including the distribution grid, in terms of system peak load, losses, voltage, and system load factor. To mitigate possible issues, different congestion management strategies are examined in this study. The current base load of customers is used as one of the main input variables, whereas the additional electrical load (e.g., from heating or batteries) is scheduled based on different objectives (e.g., minimisation of heating cost or minimisation of distribution losses) subjected to the network constraints and end-user comfort requirements.

The assessment is done through simulations of the electric load based on a large database of real-world historical data from which a number of end-users are randomly chosen. These include multi-apartment buildings, detached buildings, commercial and industrial customers, public buildings, etc. Several heating control strategies are examined, and a simplified radial distribution network topology is modelled employing a balanced three-phase power flow calculation which allows drawing general conclusions on the potential impact of SETS. For power flow calculations, common parameters of lines and transformers representative of the Latvian distribution system have been chosen.

\subsubsection{Results and Discussion}

The results from the representative feeder network modelling for the Latvian case study comprise various metrics across the scenarios, heating electrification, and SETS scheduling strategies analysed. The total number of combinations modelled is equal to $216=6$ scenarios $\times 3$ study years $\times 3$ heating electrification levels $\times 4$ ( 3 SETS strategies and reference DRH). However, only select results will be presented in this section to maintain readability. The other results will nevertheless inform the overall conclusions.

Table 3.1 summarises some noteworthy results from the Base scenario for the year $\mathbf{2 0 3 0}$. The load factor maximisation strategy as a coordinated control of SETS seems to be the most overall beneficial in terms of trade-offs to the distribution grid operator and end-users because it provides significant peak load reductions, somewhat reasonable decreases in the electricity bills (for electrified heating) and also decreased cost of energy losses in the distribution grid. 
The heating and losses cost reductions are expressed in terms of $€$ per dwelling heated by SETS, but there were also some public and business buildings in the representative feeder setup that can be electrically heated, so the reader should be advised the term 'dwelling' here refers not only to households. Also, it is crucial to point out that only the energy component of end-consumer electricity bills is considered here, which constitutes roughly $20-30 \%$ of the final bill in Latvia [39]. Renewables levies, taxes, transmission and distribution tariffs comprise the remaining part.

The second charging strategy (heating cost min.) is not a coordinated control, at least not in the sense that the SETS devices in the different houses affect each other's operation. The control in SETS - (2) strategy is solely price-based. As a consequence, all the devices strive to charge when the price is the lowest, resulting in vastly increased peak loads (which are now shifted in time). The third charging strategy, cost of losses (incurred by the DSO) minimisation, also results in increased peak load in $10 \%$ and $20 \%$ heating electrification scenarios.

Table 3.1

Impact of SETS Charging Strategy on the Grid Losses and Heating Costs, Base Scen. (2030)

\begin{tabular}{|c|c|c|c|c|c|c|c|c|c|}
\hline $\begin{array}{l}\text { Heating } \\
\text { strategy }\end{array}$ & \multicolumn{3}{|c|}{$\begin{array}{c}\text { SETS - (1) } \\
\text { load factor max. }\end{array}$} & \multicolumn{3}{|c|}{$\begin{array}{c}\text { SETS - (2) } \\
\text { heating cost min. }\end{array}$} & \multicolumn{3}{|c|}{$\begin{array}{c}\text { SETS - }(3) \\
\text { losses cost min. }\end{array}$} \\
\hline $\begin{array}{r}\text { Heating } \\
\text { electrification }\end{array}$ & $2 \%$ & $10 \%$ & $20 \%$ & $2 \%$ & $10 \%$ & $20 \%$ & $2 \%$ & $10 \%$ & $20 \%$ \\
\hline $\begin{array}{r}\text { Peak load } \\
\text { reduction, } \mathrm{kW}\end{array}$ & 11.2 & 51.5 & 150.3 & -23.3 & -263.4 & -516.3 & 12 & -108.9 & -154.6 \\
\hline$\%$ & 1.73 & 7.42 & 17.60 & -3.61 & -37.94 & -60.46 & 1.86 & -15.68 & -18.11 \\
\hline $\begin{array}{l}\text { Cost of heating } \\
\text { decrease, } € / \text { dw. }\end{array}$ & 76.13 & 38.32 & 23.63 & & 138.78 & & 131.18 & 115.79 & 97.98 \\
\hline$\%$ & 17.33 & 8.72 & 5.38 & & 31.58 & & 29.85 & 26.35 & 22.30 \\
\hline $\begin{array}{r}\text { Cost of losses } \\
\text { decrease, } € / \text { dw. }\end{array}$ & 12.26 & 7.64 & 6.65 & 15.74 & 8.40 & -0.91 & 17.05 & 13.98 & 13.13 \\
\hline$\%$ & 33.84 & 18.36 & 13.75 & 43.46 & 20.19 & -1.89 & 47.07 & 33.59 & 27.13 \\
\hline
\end{tabular}

Table 3.2

Impact of SETS Charging Strategy on the Grid Losses and Heating Costs, DSM Scen. (2030)

\begin{tabular}{|c|c|c|c|c|c|c|c|c|c|}
\hline $\begin{array}{l}\text { Heating } \\
\text { strategy }\end{array}$ & \multicolumn{3}{|c|}{$\begin{array}{c}\text { SETS - (1) } \\
\text { load factor max. }\end{array}$} & \multicolumn{3}{|c|}{$\begin{array}{c}\text { SETS - (2) } \\
\text { heating cost min. }\end{array}$} & \multicolumn{3}{|c|}{$\begin{array}{c}\text { SETS - (3) } \\
\text { losses cost min. }\end{array}$} \\
\hline $\begin{array}{r}\text { Heating } \\
\text { electrification }\end{array}$ & $2 \%$ & $10 \%$ & $20 \%$ & $2 \%$ & $10 \%$ & $20 \%$ & $2 \%$ & $10 \%$ & $20 \%$ \\
\hline $\begin{array}{r}\text { Peak load } \\
\text { reduction, } \mathrm{kW}\end{array}$ & 10.9 & 75.1 & 188.3 & -41.7 & -258.2 & -502.4 & 12 & -77.8 & -48.5 \\
\hline$\%$ & 2.23 & 12.78 & 22.27 & -8.52 & -43.95 & -59.41 & 2.45 & -13.24 & -5.74 \\
\hline $\begin{array}{l}\text { Cost of heating } \\
\text { decrease, } € / \mathrm{dw} \text {. }\end{array}$ & 30.61 & 11.88 & 6.22 & & 69.39 & & 62.81 & 43.44 & 32.15 \\
\hline$\%$ & 7.08 & 2.75 & 1.44 & & 16.04 & & 14.52 & 10.04 & 7.43 \\
\hline $\begin{array}{r}\text { Cost of losses } \\
\text { decrease, } € / \text { dw. }\end{array}$ & 4.90 & 3.01 & 3.57 & 2.37 & -3.85 & -16.68 & 7.48 & 5.28 & 5.56 \\
\hline$\%$ & 14.71 & 7.82 & 7.91 & 7.11 & -9.99 & -36.94 & 22.48 & 13.69 & 12.32 \\
\hline
\end{tabular}


The Demand-side measures (DSM) scenario in Table 3.2 shows an improved ability of SETS to decrease the peak load in the representative feeder network. However, this is likely due to the way the scenario is implemented. The reference electric heating (direct resistive) is not subjected to any demand-side measures, rather it is added to a system where the rest of electric load has already been smoothened. As a result, the DRH use causes quite pronounced peaks, which the SETS can then reduce. The monetary savings, however, are more than halved. For instance, in the Base scenario SETS can reduce the electric heating costs in dwellings by $31.58 \%$ (cost reduction strategy), while in the DSM scenario they are decreased only by $16.04 \%$.

\subsection{Modelling of SETS Impact on the Power System}

\subsubsection{Approach Overview}

The power system-scale benefit modelling employed for the Latvian case study combines the various tools and approaches developed by the Institute of Power Engineering during the implementation of RealValue project (2015-2018) and even before that. It also closely intertwines with the distribution grid model described in Section 3.2 (i.e., the DG model feeds electrical heating time series data to the system model), which, in its turn, uses the heat demand derived from building thermal modelling in Chapter 2. The overall setup for modelling SETS impact on the Latvian power system is illustrated in Fig. 3.1.

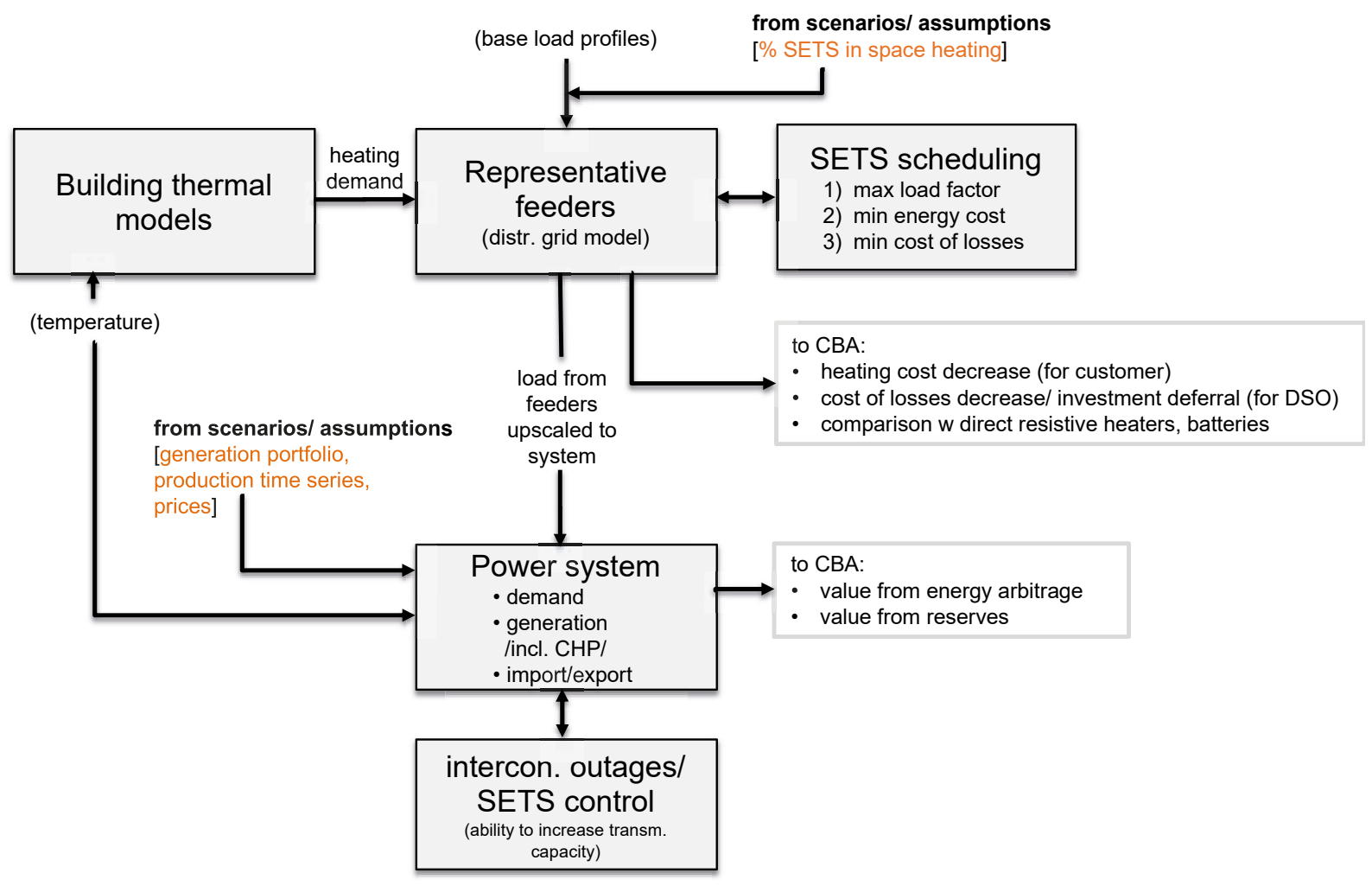

Fig. 3.1. Overall setup for SETS impact modelling. 
The geographical scope of the model covers Latvia and Lithuania, whereas heating electrification is carried out only in Latvia (i.e., no SETS in Lithuania and the benefits are also expressed solely from the Latvian power system point of view).

The SETS compared to DRH brings two beneficial effects captured by the model:

- decoupling heat demand from electricity consumption (i.e., energy arbitrage);

- provision of reserves to the power system due to SETS remote controllability.

\subsubsection{Results and Discussion}

\section{Results for 2020}

While electricity cost reduction benefits brought by SETS in the Latvian power system are explored from two different angles (arbitrage and reserves), the results below are presented in a summarised way. The benefits are identified in comparison to a reference case where heating electrification is carried out with DRH at the same penetration level. All costs and benefits are expressed per annum. In all the scenarios analysed, a trend can be established where the total electricity cost decrease from SETS arbitrage increases in both absolute and relative terms with larger heating electrification.

Fig. 3.2 combines both avenues of SETS beneficial contributions for the study year of 2020, expressed relative to the installed energy storage capacity of SETS. We can observe that the specific benefit from SETS decreases with larger penetration. In terms of benefits from SETS penetration, the $2 \%$ case offers the highest savings in the electricity system (Base scen. $-1.24 € / \mathrm{kWh}$ ), whereas if the penetration is $10 \%$ or more, the specific benefit is greatly diminished (Base scen. $-0.74 € / \mathrm{kWh}$ and $0.77 € / \mathrm{kWh}$ for $10 \%$ and $20 \%$ penetration of SETS, respectively). It can be also concluded from the various scenarios that SETS value somewhat depends on the underlying heating demand assumptions, but even more so from the characteristics and flexibility of the other electrical load and the marginal costs of pricesetting generators.

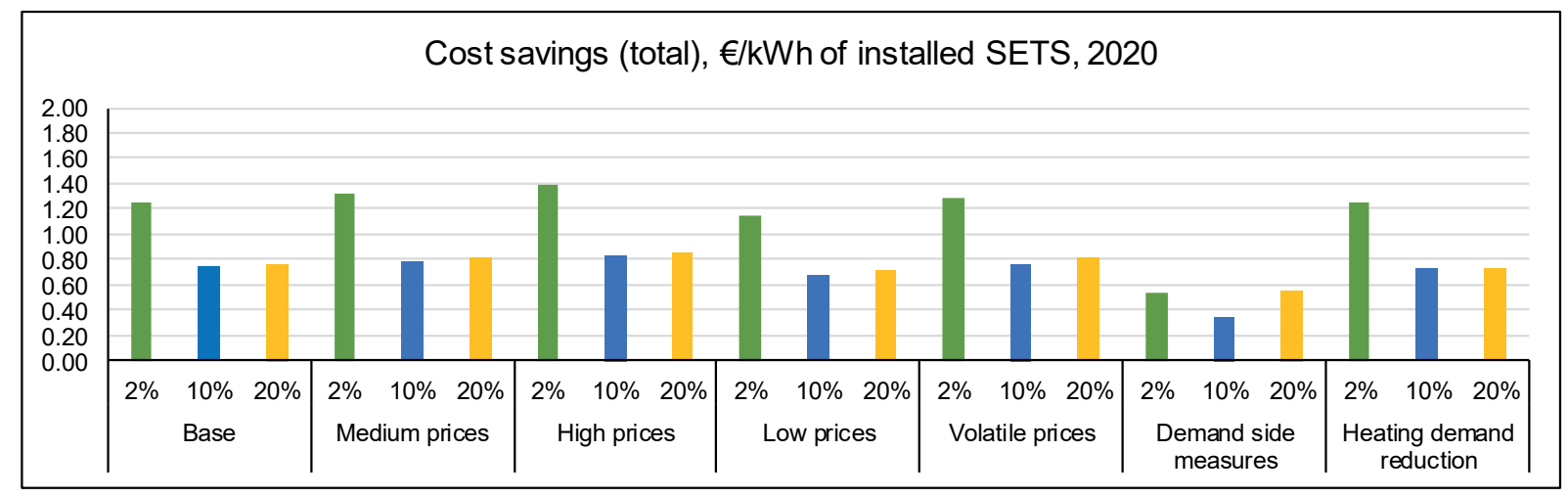

Fig. 3.2. Total costs savings from SETS per kWh of installed storage, 2020.

In Fig. 3.3, we can observe the price-reducing effects of SETS in the day-ahead electricity wholesale in the various scenarios and penetration levels. The weighted average price decreases by $0.49 \%, 1.25 \%$ and $1.88 \%$ for the $2 \%, 10 \%$ and $20 \%$ penetration levels of SETS respectively as can be seen in Fig. 3.3. This very well exemplifies the positive effect 
from SETS energy storage and scheduling abilities, i.e., moving heating-related electrical load away from the peak price periods thus smoothening the overall load curve.

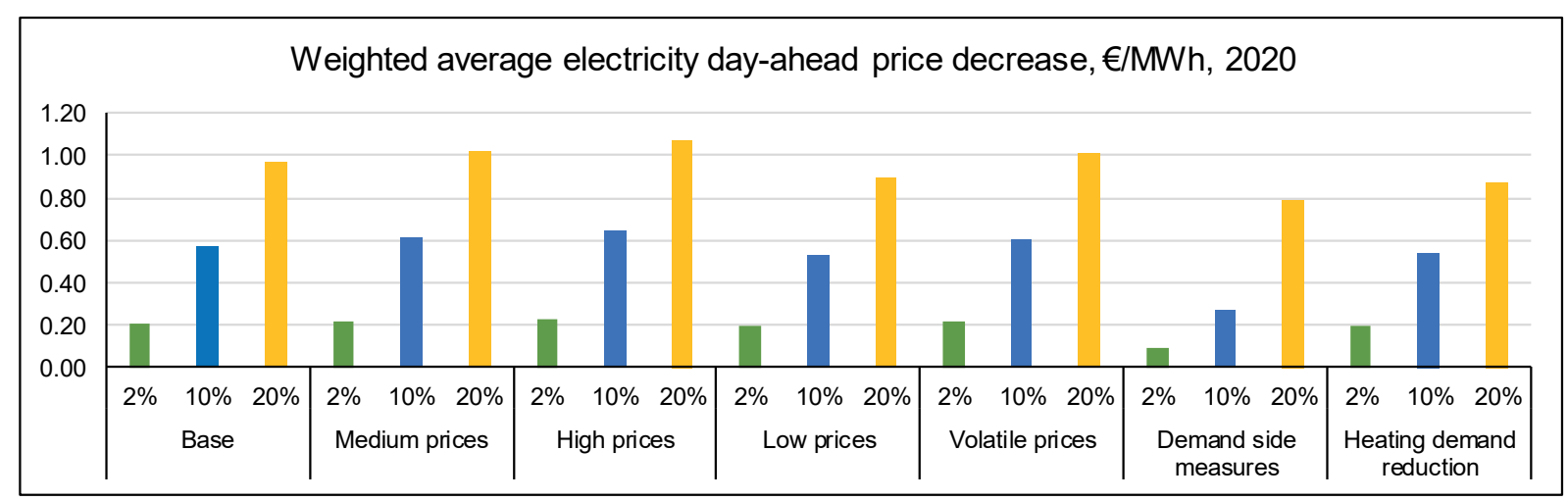

Fig. 3.3. Electricity price decrease in the Latvian bidding area with SETS.

\section{Results for 2030}

At first glance, the results for the study year 2030 show some obvious differences from the results for 2020. Firstly, the cost savings brought by SETS arbitrage are overall greater. However, the previously observed tendency for the specific benefit from arbitrage to decrease as the level of penetration rises is also seen here. In the results for 2030, we can observe much greater variation in arbitrage benefits depending on price assumptions (Medium, High and Low price scenarios) compared to 2020 . It is, however, primarily a consequence of the model setup and the fact that the price uncertainties considered here grow larger the further in future we project.

The Demand-side measures scenario, on the other hand, is similar to the 2020 case as it shows significantly lesser cost savings than the Base scenario as can be well seen in Fig. 3.4. Namely, the specific benefit decreases from $1.39 € / \mathrm{kWh}, 0.75 € / \mathrm{kWh}, 0.71 € / \mathrm{kWh}$ to $0.54 € / \mathrm{kWh}, 0.36 € / \mathrm{kWh}, 0.49 € / \mathrm{kWh}$ for the various penetration levels. Again, the previous conclusion can be reiterated so that demand without any demand-side measures applied shows greater potential for cost decrease with SETS scheduling abilities than demand which is already smoother.

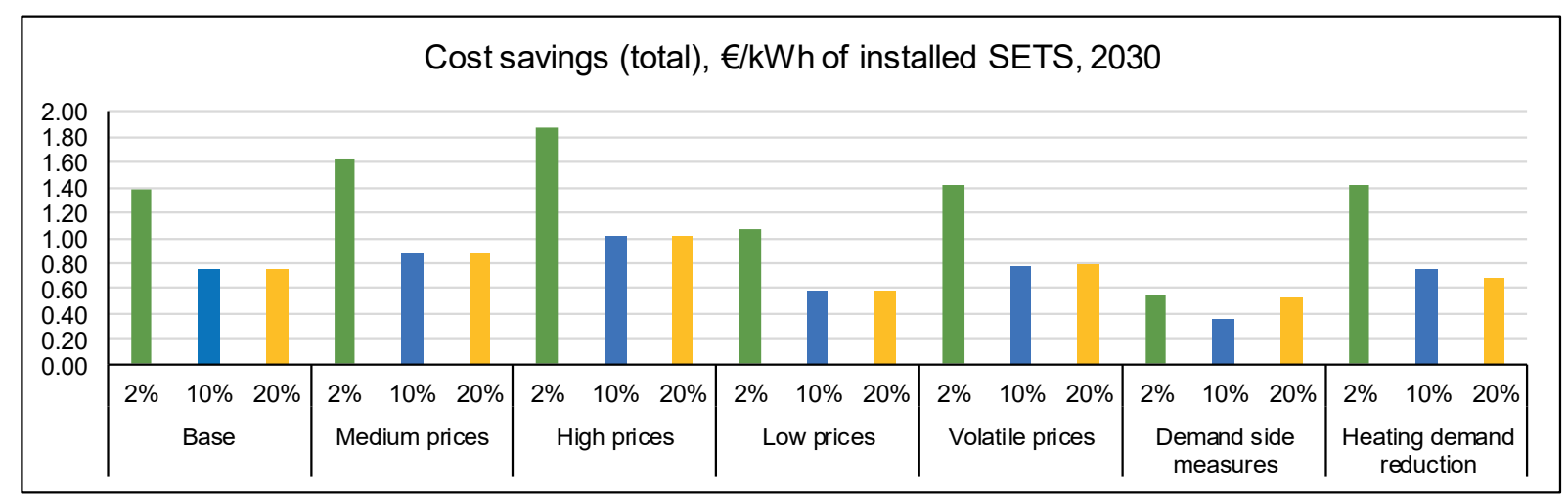

Fig. 3.4. Total costs savings from SETS per kWh of installed storage, 2030. 
Fig. 3.5 illustrates the effects SETS devices have on the electricity wholesale day-ahead price. Similarly to 2020, the larger the heating electrification level, the better SETS can decrease the electricity price if the reference electrification medium is DRH. While the average hourly price itself changes only barely (by $0.09 \%$ maximum), the weighted average experiences much more impactful reductions (by up to $1.88 \%$ ) which is very beneficial to all the electricity consumers but might not necessarily be a good sign to electricity producers, especially those who do not have much flexibility in their production scheduling.

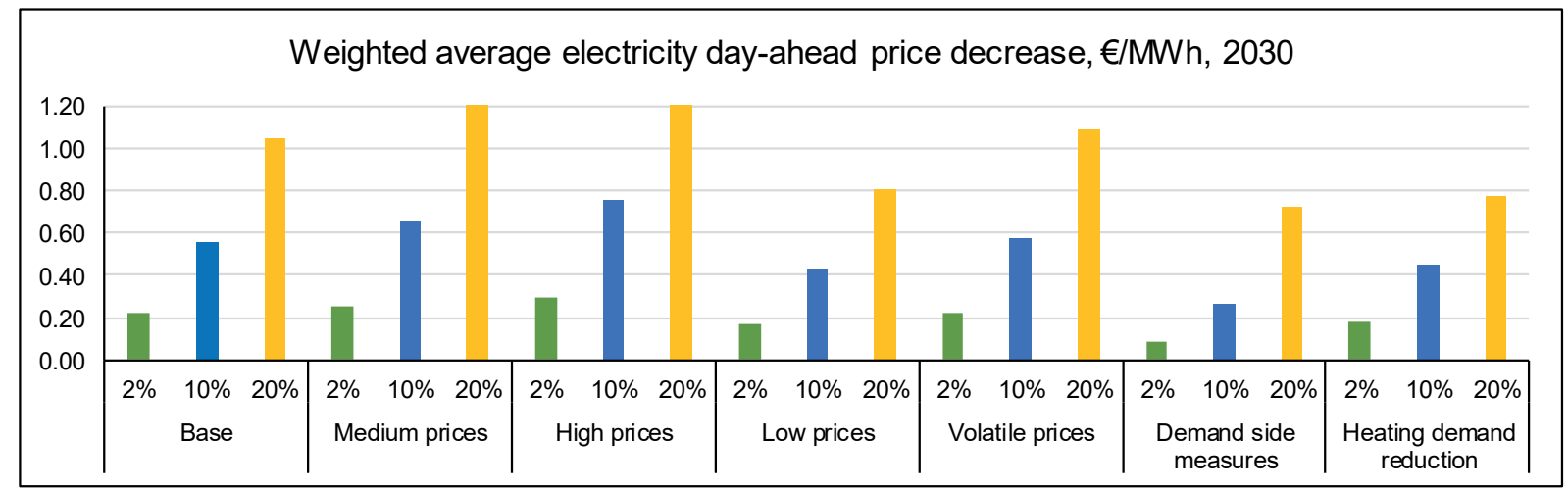

Fig. 3.5. Electricity price decrease in the Latvian bidding area with SETS.

\section{Results for 2050}

The e-Highway sensitivities for the 2050 study year (Fig. 3.6) were also analysed from the same two vehicles of electricity cost savings as in the previous two study years - arbitrage and reserves.

The 2050 scenarios differ from 2020 and 2030 assumptions most importantly by majorly increased renewable generation, especially intermittent sources like wind and solar. Of course, modelling so far in the future must be taken with a grain of salt, nevertheless the results obtained here might provide some valuable insights.

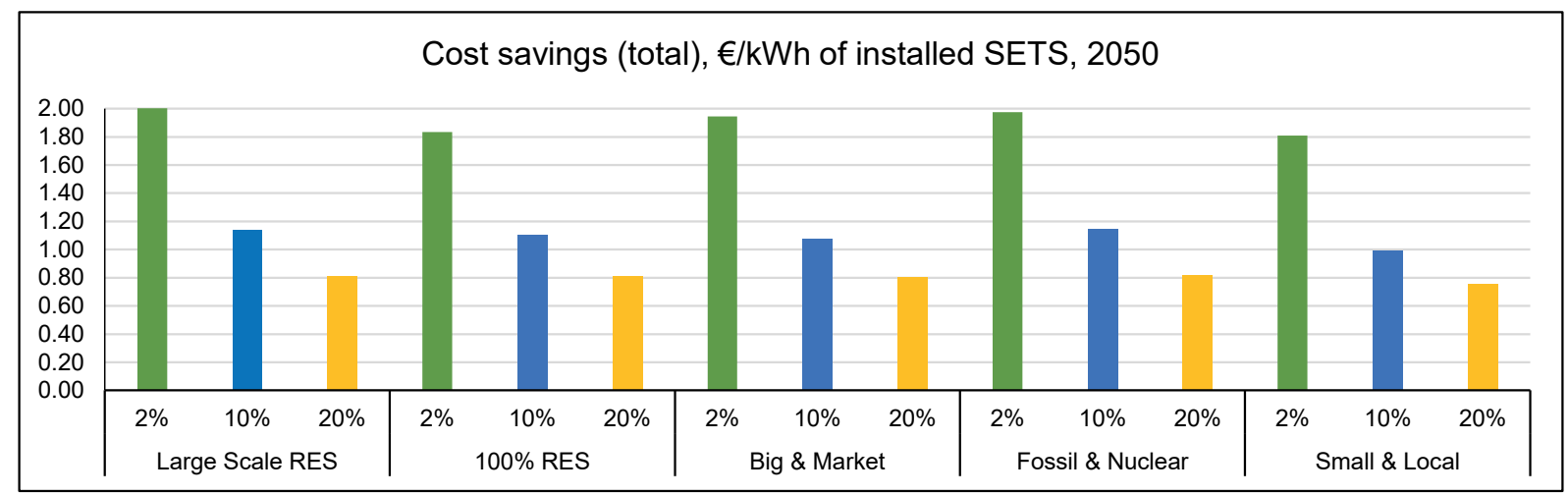

Fig. 3.6. Total costs savings from SETS per kWh of installed storage, 2050.

The annual electricity demand also is notably higher in the 2050 scenarios than in either of the prior study years. The benefits from arbitrage are lower in relative terms (savings versus total costs) but overall higher in absolute values or per units of SETS consumption or capacity. From the five scenarios compared, Small \& Local finds the least specific value from 
SETS per kWh of installed capacity, whereas in the Large Scale RES scenario the specific value is the highest varying between $2.00-0.81 € / \mathrm{kWh}$ for $2-20 \%$ penetration of SETS, resp.

\subsection{Summary}

To investigate the impact of local small-scale thermal electric storage on the low voltage distribution network congestions, a model representing general characteristics of the Latvian distribution grid and typical electrical loads of end-users has been developed assuming partial electrification of heating with SETS or direct resistive heaters. To mitigate the possible issues of heating electrification, several congestion management strategies have been studied that strive to either minimise daily load variance, decrease overall losses or minimise the cost of heating for customers.

The increased demand resulting from the electrification does induce notably higher electricity costs in the system, especially in the $10 \%$ and $20 \%$ cases. However, evidently, these cost increases can be somewhat alleviated if the electrification is carried out with smart electric thermal storage instead of direct resistive heating.

Most of the value that SETS bring comes from their smart storage ability, i.e., mostly charging in times when the electricity price/demand is lower and discharging whenever the heating energy is required which allows avoiding electricity consumption at the usual peak times. However, this also exemplifies that SETS contribution to system benefits can be expected to be lower if the peak/off-peak characteristics of the overall demand curve have become less pronounced due to other developments on the demand-side of the power system. This expectation was indeed confirmed by the Demand-side measures sensitivity. Improvements in thermal efficiency / heat demand reduction measures also signify lesser deployment of SETS devices and diminished benefit from them. The benefit from each SETS unit installed also decreases the more of them are deployed in the system.

From the distribution grid operator's perspective, partial heating electrification does bring the risk of congestion and increased need for investments to avoid it. However, coordinated scheduling of SETS does serve well in alleviating most of these concerns as shown in the representative feeder study. Furthermore, it also aids in decreasing the cost of losses for the DSO and reasonably reduced electricity bills to the end-consumers when compared to the baseline of electrification with DRH. However, some caution is necessary because if the control of SETS is not coordinated for grid benefit but only follows the electricity price signal to decrease the end-user bills to a minimum, it causes massive issues to the distribution grid in terms of peak power, load factor, and necessary grid reinforcements. 


\section{ECONOMIC ASSESSMENT OF RESIDENTIAL-SCALE DR}

\subsection{Motivation and Background}

The EU had already set itself ambitious targets for decarbonisation and climate change mitigation, but on June 2018 a move was made to raise the aspirations even higher by envisioning a $32 \%$ share of renewable energy in the total consumption within the EU by 2030 [40]. However, the increasing adoption of renewable energy resources poses new challenges to successful and reliable operation of electric power systems. Some of the issues created by increased penetration of distributed and renewable energy sources (especially solar and wind) within power systems are caused by the stochastic nature of their energy production, i.e., frequency control and balancing issues, also power quality problems, which affect both power system real-time operation and the planning of future developments on the distribution grid as well as the transmission network level [41], [42].

While solutions to the emerging issues can be sought on the power generation, transmission or distribution side, the demand side also offers promising measures for mitigating the increasing stochasticity of power system operation [12]. Demand response (DR) has been identified as a particularly attractive tool power system operators could use for system control and management by offering incentives to consumers via so-called explicit DR where the DR asset owner is remunerated in either a classic direct control/interruptible load program or from an ancillary service/capacity market [10], [43], [44]. Furthermore, indirect encouragement of consumers to adapt their behaviour for overall power system benefit by their voluntary exposure to electricity real-time prices or some other price-based programs via implicit DR can bring some effect in coupling consumption patterns to generation availability [45], [46].

There are several benefits DR can bring to the system, e.g., provision of ancillary services, contingency management, price volatility reduction, investment cost deferral, etc. [12], [44], [37]. While, in general, this topic is widely studied in recent literature in the context of the ongoing transition to the Smart Grid paradigm [10], there is nevertheless still some uncertainty in terms of DR implementation. Small individual loads do not have much influence on the overall system operation, hence their control has to be aggregated to reach the required minimum balancing power bid size. This is usually done by an aggregator which is an entity that pools together the flexibility resources of several consumers and offers them to a marketplace or an operator directly [48].

While the reserve and regulating power markets do offer new and exciting possibilities for small consumers to participate in developing DR markets, the insufficiently clear rules regarding resource aggregation provide an apparent obstacle [12], [49]. Luckily, the situation is improving and policy-makers and power system operators throughout Europe are working on more efficient utilisation of potential DR resources. For instance, it is increasingly viewed as an important and underutilised asset in the Baltic region [50] that could help to improve the energy independence and diversify the flexibility resources offered on the Baltic balancing market [51]. Moreover, the EU Clean Energy Package also calls for the involvement of demand-side resources in all electricity markets. 
How widespread DR implementation can influence the operation of electric power systems is a subject already extensively studied in the literature. While there are some associated risks identified (e.g., pronounced rebound effects with time-varying electricity prices [52]), most sources come to the conclusion that DR programs have the capability to reduce the overall power supply costs [53]-[56]. However, the economic effect of DR on the DR asset owners (i.e., householders or businesses with flexible load) is paid somewhat less attention to, some notable work being presented in [56]-[60]. Furthermore, in some cases, current market structures and incentives seemingly either fail to provide meaningful economic benefit to DR asset owners or only result in minuscule profitability [46], [49], [61], [62].

On the one hand, for electricity end-users to become interested in DR provision, they need to be aware of the potential benefit they can gain. On the other hand, proper incentives need to be introduced for customers to participate in DR programs. However, the modelling of DR operation required for economic feasibility evaluation is quite complicated. An important issue, which should not be neglected, is load recovery when consumers change their consumption patterns in the hours following a DR event [63]. Another peculiarity arises when modelling the flexibility potential of a consumer and uncertainties related to it [64]. Uncertainty is also a factor concerning the stochastic behaviour of prices in electricity markets and system imbalances. To that end, Monte Carlo simulations have proven to be an effective approach to handle modelling uncertainties [65]. Based on the above-mentioned considerations, a bespoke tool was developed to aid the potential DR providers in assessing the benefits from their participation in a DR program or electricity market.

\subsection{Methodology}

For assessment of DR economic potential from the DR asset owner's perspective, a software tool was developed using the MATLAB scripting environment [66]. The tool, DR Assess, establishes the potential economic benefit the owners of controllable load assets might achieve should they agree to participate in a DR program, for example, by having their load remotely reduced or increased to meet system balancing needs, thus providing explicit DR. Development of DR Assess tool was commissioned by the Lavian TSO, "Augstsprieguma tikkls" AS, within the research contract work "Development of mathematical models for economic assessment of demand-side flexibility resources and activation optimisation of balancing reserves". Elaboration of DR Assess took place during 2017/2018.

The main computational principle of this software lies in a Monte Carlo simulation-based approach for modelling the activations of DR and the related cash flows within a full year of the asset's operation. Consequently, the output of the model is in the form of probability distributions instead of one deterministic result as implying absolute certainty would be unreasonable when considering future processes.

The sequence of operations performed during a model run can be broadly summarised by the steps illustrated in Fig. 4.1 where day-ahead rescheduling is optional and was used only for the case study in Section 4.4. 


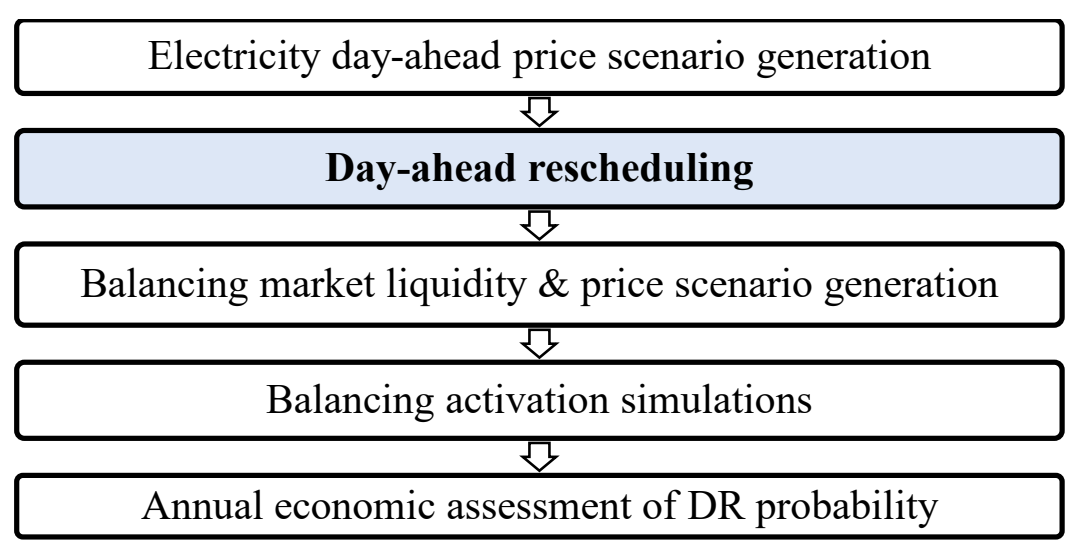

Fig. 4.1. DR Assess algorithm structure with optional implicit DR.

\subsection{Case Study on Participation of Residential DR in Balancing Market}

This section presents the first case study performed with the DR Assess tool. The model tackles uncertainties in electricity market prices and system imbalance by employing Monte Carlo simulations. While the model provides vast customizability options, this case study is focused on the potential demand response benefits for a particular type of consumer with smart electric thermal storage. It is found that participation of DR in the balancing market can be economically feasible for the asset owner, but on the condition that sufficient proportion of the balancing remuneration is shared with the owner by the aggregator.

\subsubsection{Assumptions}

The case study aims to apply our developed software tool for the economic assessment of smart electric thermal storage (SETS) participation in DR. The subject of the study is a hypothetical household having five SETS devices at their disposal with $2.2 \mathrm{~kW}$ input power and $15.4 \mathrm{kWh}$ storage capacity each. The owner is not balance responsible and is willing to participate in both upward and downward DR (which requires the SETS equipment to never be disconnected from the outlet and the gateway). We assume the asset service life is 15 years, discount rate $-3 \%$, CAPEX $-200 €$ (to cover gateway costs), and annual F-OPEX - $20 €$ (service and other related costs). For simplicity sake, it is implied for now the householder purchases electricity at wholesale price. It is also assumed that the aggregator passes on to the DR asset owner the full amount of TSO payments for load reduction (however, the effect of this assumption will be explicitly addressed).

In regard to the load profile and flexibility, we set a maximum number of $14 \mathrm{DR}$ activations per week but do not restrict the time between them. In this study, we do not allow for multi-hour DR events. Maximum duration before load recovery is set to 12 hours and the recovery factor is set to 0.9 both for load reduction and increase (this implies some energy savings in case of load reduction and some wasted energy in case of increase).

The seasonal heating demand data is derived from building thermal modelling presented in Chapter 2, where it was seen that the overall heating demand in summer, spring and autumn is approximately $10 \%, 50 \%$ and $20 \%$ of the winter demand respectively. 
The day-ahead price scenario generation settings for this case study were derived from the analysis of the Nord Pool Latvian bidding area prices during the period of 01.06.2017.31.05.2018., while the balancing scenario settings were derived from the common Baltic balancing market data (the market was launched on 01.01.2018.). The generated hourly dayahead market and balancing prices across all the thousand scenarios are summarised in Fig. 4.2 .

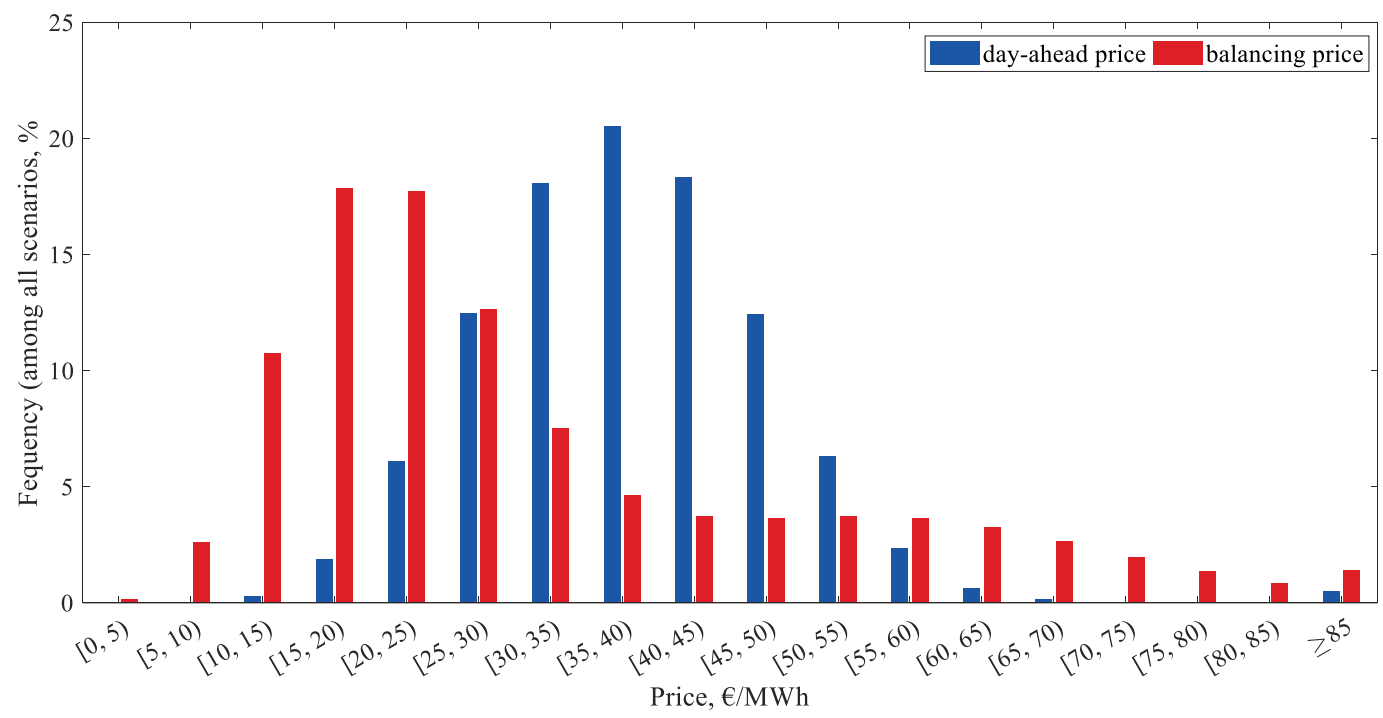

Fig. 4.2. Day-ahead and balancing market price histograms.

\subsubsection{Results and Discussion}

Though the simulation results imply there have been much more DR activations for load increase than for load reduction (on average, 452 times for increase and 199 for reduction, see Fig. 4.3), Fig. 4.4 suggests that the reduction operations have been overall more economically beneficial (scenario average of $46.50 €$ vs $12.71 €$ ).
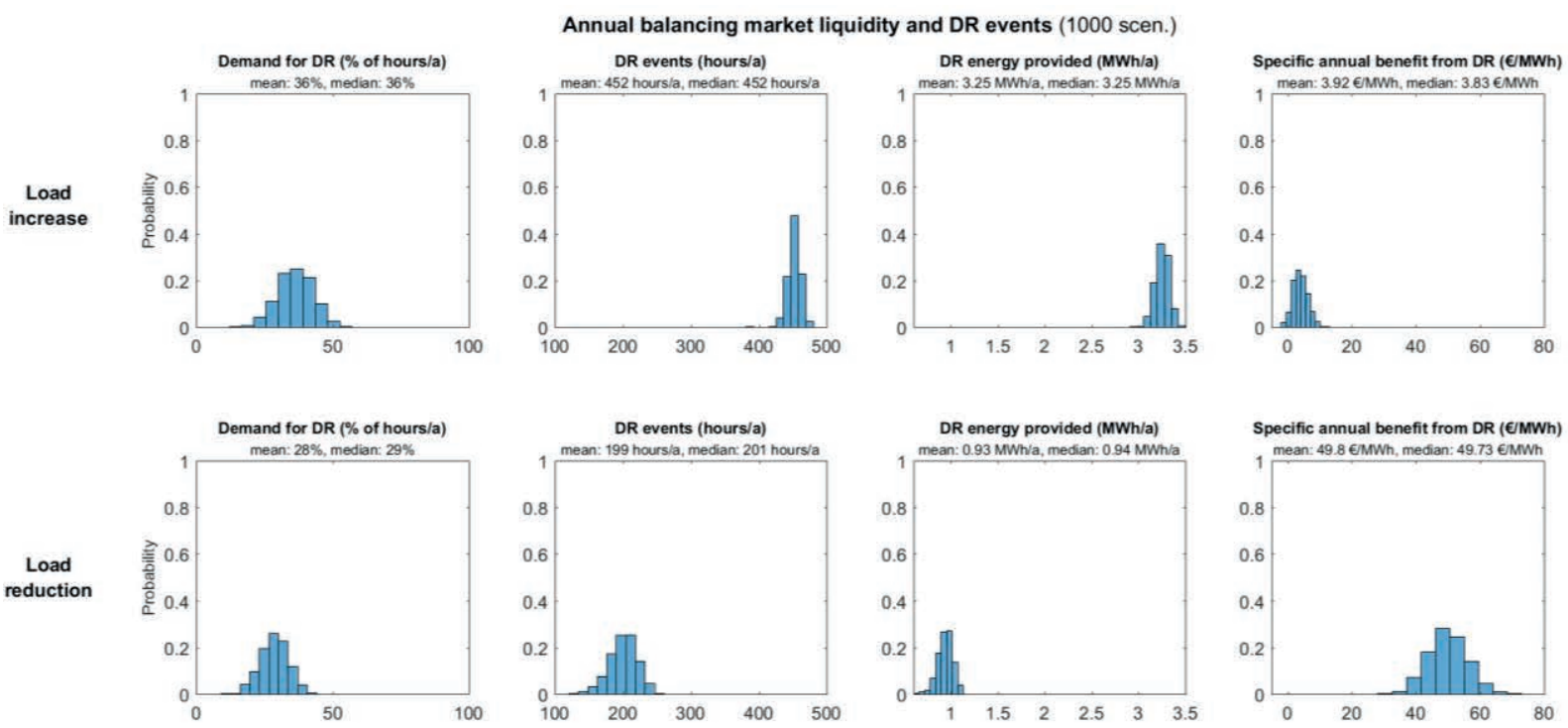

Fig. 4.3. Summary of the annual demand for DR, simulated DR events and benefit thereof. 
This is also reflected in the specific benefit in respect to provided DR energy - on average, mere $3.92 € / \mathrm{MWh}$ for increase vs $49.80 € / \mathrm{MWh}$ for reduction (Fig. 4.3). It can primarily be explained by two factors, the additional positive cash flow component in case of load reduction (Fig. 4.4) and the initially assumed load recovery factor 0.9 for both directions, which implied that load increase DR is slightly wasteful in terms of energy consumption.

While the average NPV is at 268.10€, Fig. 4.4 and Fig. 4.5 nevertheless show that there are some scenarios (3.6\%) where the NPV is still negative at the end of the selected service life ( 15 years). The average IRR is $17.56 \%$. The average payback period is thus 7.23 years while the median is 6 years, which signals that the outlier scenarios are likely skewing the mean. Indeed, Fig. 4.6 shows that some of the outlier scenarios have not reached payback even by year 20 .
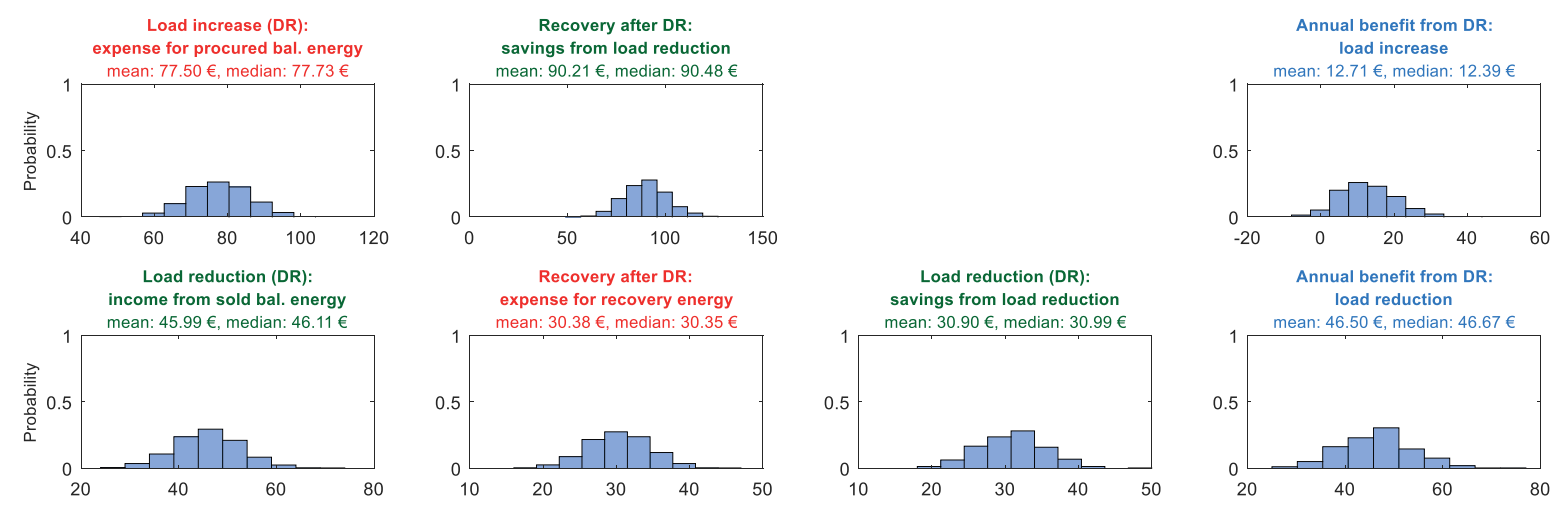

Fig. 4.4. Economic assessment for a single modelled year.
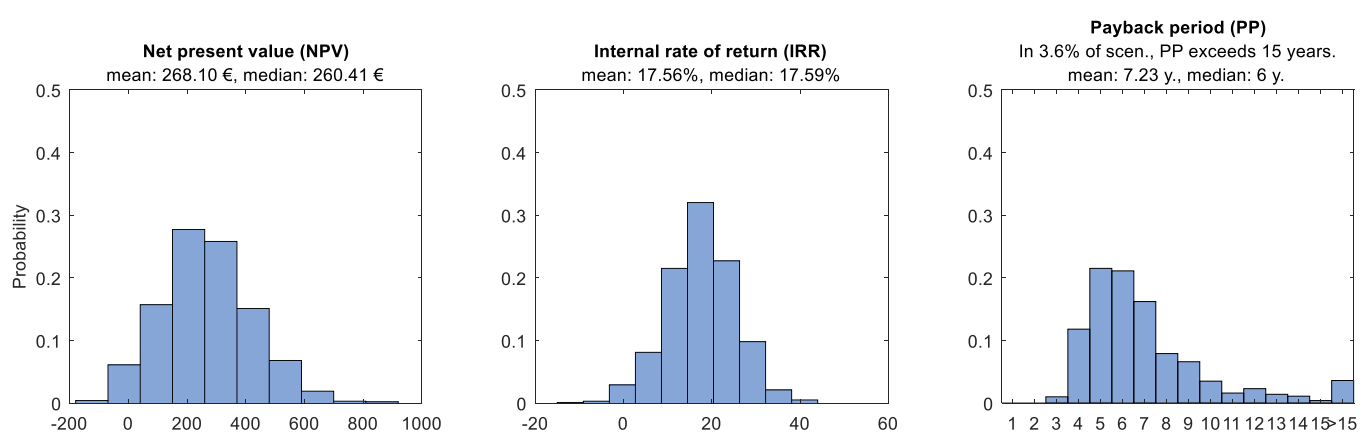

Fig. 4.5. Long-term economic assessment for the asset service life (15 years).

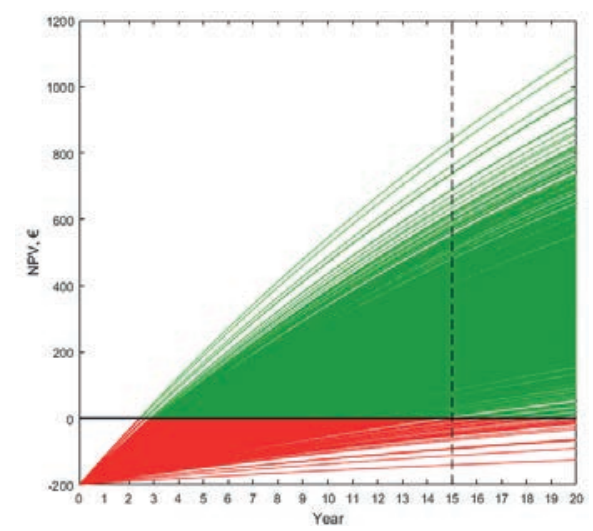

Fig. 4.6. Cumulative cash flows in all the simulated scenarios. 


\subsection{Case Study on the Benefits of Explicit and Implicit DR}

Participation of DR in ancillary services (i.e., explicit DR), which was the focus of the previous case study, is not the only way to benefit from load controllability. Implicit DR, when consumers voluntarily adjust their consumption according to external price signals (e.g., optimising load schedule as per hourly electricity prices), can also provide notable benefit [46], and the entry barriers are significantly smaller, e.g., no definitive need for aggregation. Technical capability to reschedule load and incentivising tariff structure are the only requirements for implicit DR.

Therefore, this case study is focused on analysing the profitability of participation in both explicit and implicit DR from the perspective of the owner of flexible load assets on a householder level. Furthermore, it is tested whether price-based optimisation of the flexible consumption schedule negatively affects the ability and profitability of participation in explicit DR, particularly focusing on the balancing market. The investigation, based on DRenabled smart electric thermal storage heaters, allows concluding that implicit DR does not necessarily hinder the ability to provide ancillary services to the power system. Instead, it adds a supplemental benefit to the asset owner. Besides, an investigation on the "optimal" number of Monte Carlo scenarios to be used is carried out and some considerations regarding the bidding strategy of the DR asset owner are provided.

\subsubsection{Methodology for Assessing the Benefit From Implicit DR}

For assessment of the potential benefit obtainable from participation in explicit DR programs for system balancing, the methodology introduced in section 4.2 is employed. However, it is reasonable to assume that a consumer possessing some amount of consumption flexibility would primarily be interested in taking advantage of the time-varying electricity prices. For this purpose, the DR economic potential assessment model has been enhanced with the ability to assess also the benefit from implicit DR (i.e., purchasing electricity at dynamic hourly prices, which are known the day before) as shown in Fig. 4.1. In essence, sequential hourly day-ahead optimisation is performed for the whole year with the objective to minimise electricity purchase costs, constrained by the total daily consumption which remains unchanged. When the day-ahead price-based rescheduling is modelled, the flexibility profiles available for balancing are readjusted accordingly before performing explicit DR activation simulations. The overall consumption flexibility bounds remain the same, while the load profile is changed as per the results of the price-based optimisation.

\subsubsection{Assumptions}

The case study is based on thermostatic load, which has been identified in the literature as one of the most promising load types for residential DR applications [67]-[69]. Particularly, we model smart electric thermal energy storage devices (introduced in Chapter 2) able to receive external control signals (e.g., from an aggregator). The rated input power of each device is $2.2 \mathrm{~kW}$, and, similarly to the previous case study, we assume a 
household with five units installed. The default behaviour (no gateway connection) envisions electricity consumption (i.e., storing thermal energy) in the first hours of each day, as the good thermal insulation of heaters allows the heat to be released when necessary throughout the day. Variable OPEX is disregarded in this study, but fixed OPEX is set to $20 €$ per annum.

Four different consumption and flexibility profiles for a week are used in the study to capture seasonal differences (the year is divided into four 3-month seasons). Heat energy demand is derived from building thermal modelling results in Riga, Latvia, suggesting that the average heat demand in spring is about $50 \%$ of the winter load, autumn $-20 \%$, summer $-10 \%$. In terms of flexibility, we assume that any idle heater units can be turned on and any working units switched off for one hour up to 14 times a week if there is enough flexibility in the opposite direction for recovery to be completed within the next 12 hours. Summer is an exception - we assume that only one additional heater unit can be turned on for load increase DR. The model has hourly resolution, and DR event duration is also set to one hour. The recovery effect is characterised by $k_{\text {rec }}^{\text {incr. }}=0.9$ and $k_{\text {rec }}^{\text {red. }}=0.9$, i.e., load increase DR results in slightly wasted energy, whereas load reduction DR manifests some energy savings.

The day-ahead price scenario generation is based on statistics in the Latvian price area of Nord Pool (01.11.2017.-31.10.2018.), and the parameters for balancing market scenarios are derived from the common Baltic balancing market data (01.01.2018.-31.10.2018.). The owner of the flexible load purchases electricity for its regular consumption at a dynamic retail price defined as $\Pi_{\text {ret. } t}=1.21\left(\Pi_{\mathrm{DA} t}+62.91\right)$, which is a representative electricity retail tariff in Latvia at the time of conducting this study (November 2018) composed of the hourly day-ahead wholesale price $\Pi_{\mathrm{DA} t}$, trade commission, mandatory procurement component, distribution tariff, and a $21 \%$ value-added tax on top.

For comparability, all the calculations within this study have been performed using the same 1000 scenarios for the day-ahead and balancing market (i.e., they have been generated only once). The distributions of the hourly prices generated are summarised in Fig. 4.7.

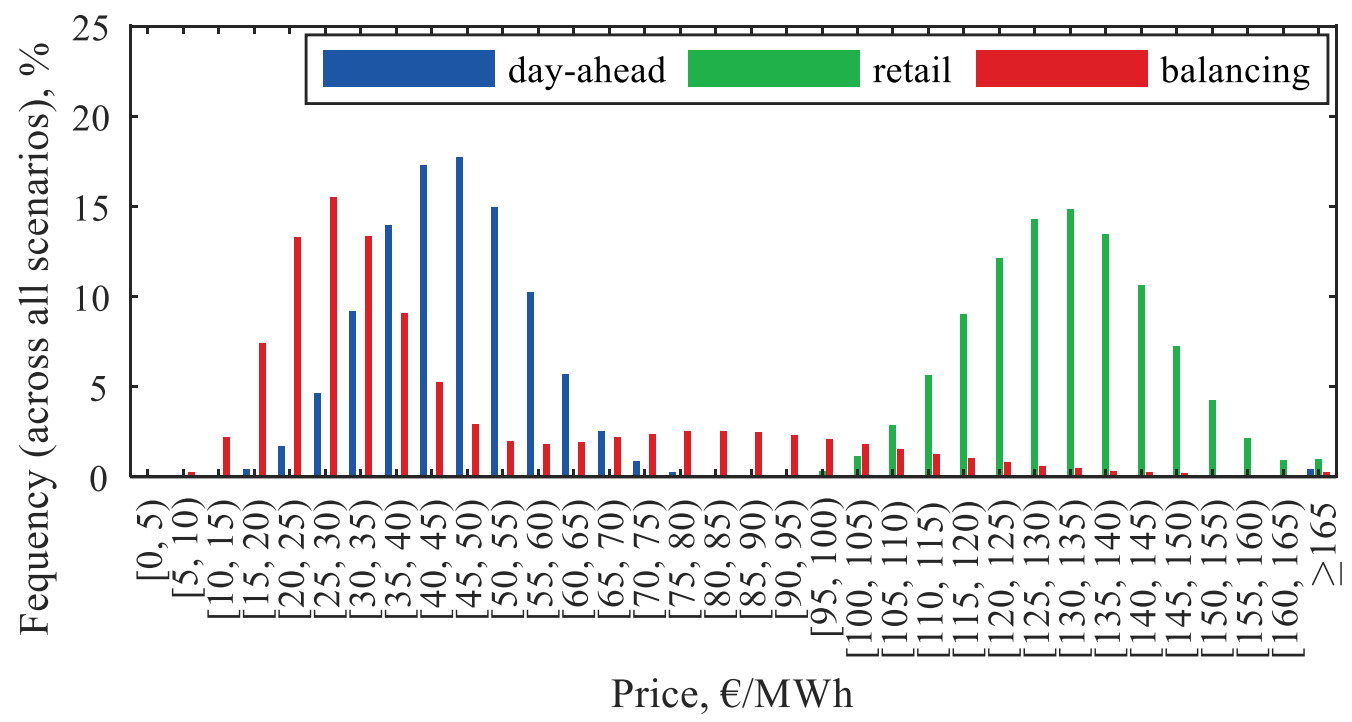

Fig. 4.7. Histogram of electricity prices. 


\subsubsection{Results and Discussion}

For comparison purposes, we carried out two model runs - firstly, with only explicit DR for power system balancing, assuming aggregated DR capability to participate in the mFRR market in the Baltics, and, secondly, with additional implicit DR implemented by price-based rescheduling of the consumption on a day-ahead basis, before participation in the balancing market.

Fig. 4.8 summarises the modelled scenario results in terms of the positive and negative annual cash flow positions incurred due to explicit DR activations for a case where the initial consumption has not been price-optimised. When compared to the same indicators for a case where there has been a day-ahead rescheduling performed beforehand (Fig. 4.9), three main implications can be inferred.

Firstly, the benefit from implicit DR is well comparable to that from explicit DR (e.g., $74.67 €$ from rescheduling, 336.16€ from balancing DR). Secondly, implicit DR does not negatively affect the profitability of participation in explicit DR but supplements it instead. Thirdly, the cash flow components directly dependent on the hourly retail price are most affected by the day-ahead rescheduling.
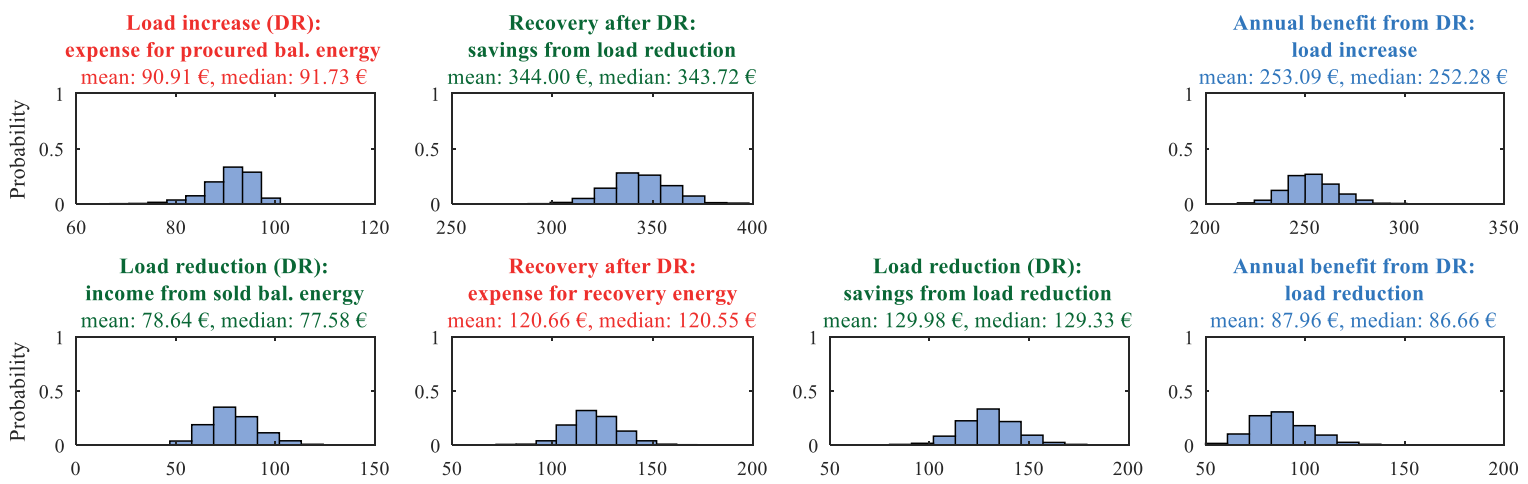

Fig. 4.8. Probability histograms of the modelled cash flow positions (red - positive, green - negative, blue - total) without day-ahead rescheduling.
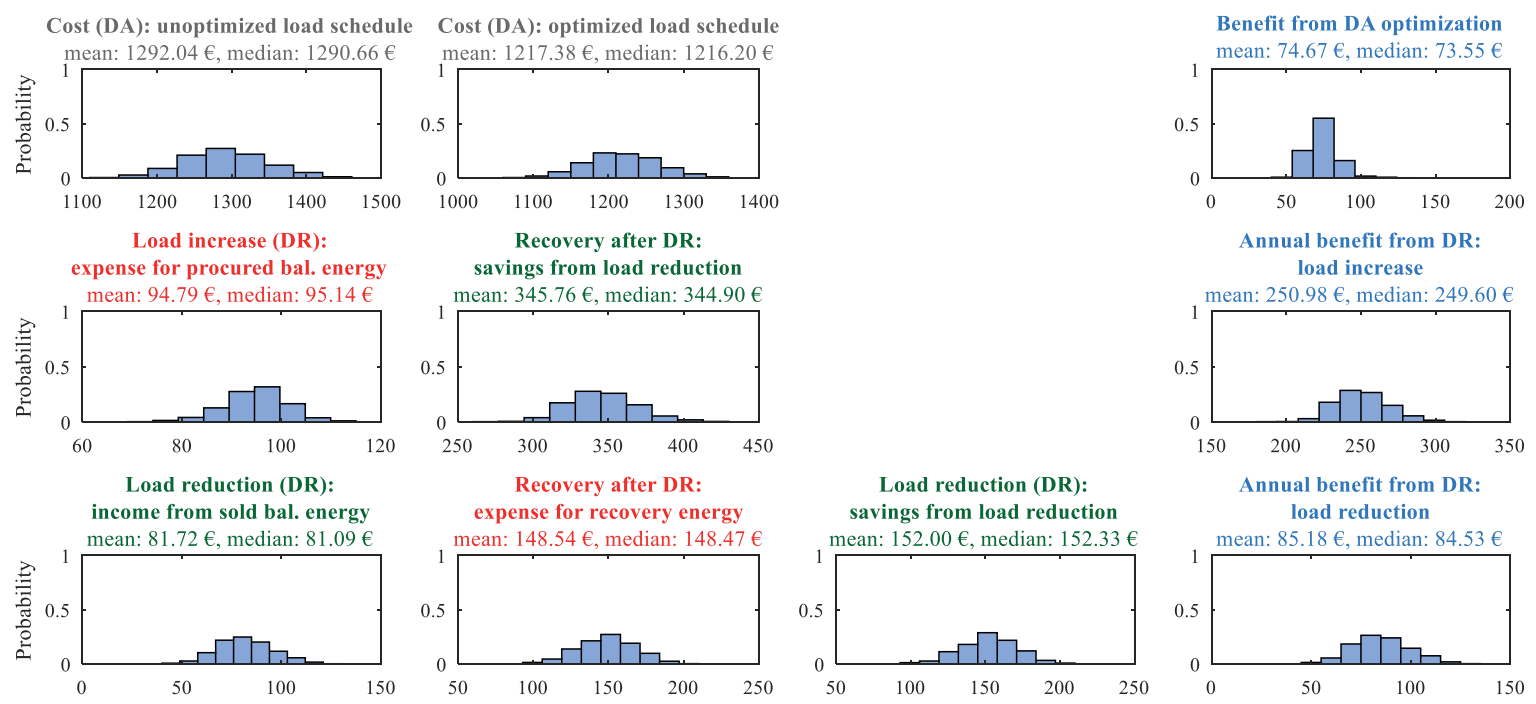

Fig. 4.9. Probability histograms of the modelled cash flow positions (red - positive, green - negative, blue - total) with day-ahead rescheduling. 


\subsection{Summary}

The developed Monte Carlo simulation-based DR economic assessment tool DR Assess has proven to be useful in providing a preliminary evaluation of the potential benefits a controllable load asset owner might gain by participating in the power system balancing via an explicit DR program and, additionally, by optimising its load schedule based on the dayahead market prices (i.e., implicit DR). However, the model employed requires quite detailed knowledge of the technical characteristics of the DR asset, especially in regard to its available flexibility with an hourly resolution. In general, the results are assumption-sensitive, thus any output should not be viewed independently of the input.

The DR economic assessment model also allows studying the benefit from explicit DR by its components - balancing payment, efficiency increase (or decrease), and hourly price variations if a dynamic retail tariff is used. While the last two components provided a negative effect in some of the case studies, albeit the sum cash flow remained positive in all cases, thus rewarding the DR asset owner with financial benefits.

The results from the case study on participation of residential DR in balancing market signal that electric thermal storage devices can recoup the additional investments necessary to make them DR-ready, but only if more than $50 \%$ of the load reduction remuneration is passed on to the asset owner. In fact, the stochastic output of the model shows that even at $100 \%$ remuneration, there is a small probability that the payback period could exceed the asset service life. Realistically, however, such a full payment sharing is unlikely as the aggregation service provider also needs incentives for its operation.

Furthermore, the case study on providing both explicit and implicit DR by employing smart electric thermal storage devices allows to draw the conclusion that, being subjected also to implicit DR by means of price-based consumption rescheduling, does not impede the overall profitability of explicit DR. While the parameters of DR activations and related cash flows do change, the sum benefit remains similar in both cases. Moreover, the exposure to implicit DR itself adds notable supplemental benefit to the overall profitability of DR-enabled smart electric thermal storage heaters. It was also demonstrated how the DR Assess tool can be used for identification of reasonable bidding price selection for explicit DR activation for system balancing purposes. Evidently, for load reduction, activation price constraints are not strictly necessary as long as the variable OPEX induced by DR is minuscule.

In conclusion, a more realistic DR economic feasibility assessment would require near perfect beforehand knowledge of the contractual setup between the DR asset owner, aggregator, BRP, TSO and other potentially linked parties. However, the regulatory and market framework for DR aggregators in Latvia is still under development. To that end, the DR Assess tool allows modelling a variety of different setups which enables studies on finding the most suitable business case for a particular application. It could also be used by policy-makers to analyse the potential implications for the involved parties of different regulatory conditions. Further studies should aim to expand the DR assessment model to consider other potential markets and forms of explicit DR where residential-scale customers might participate in an aggregated form since currently the model is focused solely on an mFRR product-based balancing market. 


\section{CONCLUSIONS}

1. The assessment of benefits obtainable from demand response and results of the balancing process optimisation confirm the hypothesis of the Doctoral Thesis. The proposed solutions have proven to be able to increase the flexibility of the power system and improve its operational efficiency.

2. The developed methodology and software tool, AOF parameter search, for optimising the activation process of balancing resources within the common Baltic balancing market framework allows significantly reducing the Baltic area control error, thus promoting cost-effectiveness and energy-independence of the Baltic power systems.

3. Power system and end-user benefits from employment of demand response have been assessed based on the example of smart electric thermal storage (SETS) as a DR-enabled innovative technology. Results show that, compared to conventional (direct resistive) heating, SETS can provide cost savings both to the Latvian power system as a whole and to individual end-users with most of the value coming from their smart storage ability.

4. Additional value stream of SETS identified in the Thesis is reserve provision to the power system. However, in the future, this value can be expected to decrease with improvements of interconnections between Latvia and Estonia and, additionally, with introduction of additional storage capacities in the Baltic power system.

5. If partial electrification of heating is envisioned in Latvia, potential distribution grid congestion risks can be significantly alleviated through coordinated scheduling of SETS as demonstrated in the representative feeder study. This also allows decreasing the cost of losses for the DSO and reducing the electricity bills for the end-consumers.

6. Notwithstanding the benefits identified in the case study for Latvia, the investment cost of the particular technology considered (SETS) is still too high for the end-user to have a positive total cash flow. Therefore, novel business models (e.g., service-based) and new revenue streams (e.g., capacity payments for DR provision) would be required for this specific technology to become financially attractive to end-users.

7. The developed Monte Carlo simulation-based tool, DR Assess, provides a probabilistic assessment of the economic feasibility of DR provision from its asset owner point-of-view. It allows considering uncertainties of electricity markets and can be applied for different types of DR assets, provided their flexibility profile is known. The tool, being able to study the effects of both implicit or explicit DR, can be particularly useful for prospective Baltic balancing market entrants by providing them with a reliable cost-benefit assessment.

8. Case studies performed with the DR Assess tool in the Doctoral Thesis were focused on residential-scale DR. It was shown that its profitability is highly dependent on the share of remuneration passed to the DR asset owner by the aggregator and is even more so dependent on the flexibility settings for a particular DR asset. Furthermore, it can be concluded that implicit DR adds supplemental benefit to explicit DR provision.

9. Future studies should aim towards investigating additional value streams for demand response to become more attractive and towards studying additional emerging market frameworks where the value of DR could be unlocked. Furthermore, the potential of industrial demand response should be examined together with the related cash flows. 


\section{REFERENCES}

[1] "Memorandum of Understanding on the Baltic Energy Market Interconnection Plan," 2009. [Online]. Available:

https://ec.europa.eu/energy/sites/ener/files/documents/2009_bemip_mou_signed.pdf. [Accessed: 18-Sep-2018].

[2] "Baltic Energy Market Interconnection Plan. Final report," 2009. [Online]. Available: https://ec.europa.eu/energy/sites/ener/files/documents/2009_11_25_hlg_report_170609 0.pdf. [Accessed: 18-Sep-2018].

[3] BEMIP, "Baltic Energy Market Interconnection Plan. 5th progress report," 2013. [Online]. Available:

https://ec.europa.eu/energy/sites/ener/files/documents/20140225_5rd_bemip_progress_r eport.pdf. [Accessed: 25-Apr-2018].

[4] Arturs Purvins; Gianluca Fulli; Catalin Felix Covrig, "The Baltic Power System between East and West Interconnections," 2016.

[5] "Augstsprieguma tīkls" AS, "Technical scenario for Baltic grid sinchronisation approved in Brussels," 2018. [Online]. Available: http://ast.lv/en/events/technicalscenario-baltic-grid-synchronisation-approved-brussels. [Accessed: 18-Sep-2018].

[6] "Augstsprieguma tīkls" AS, "Baltic TSOs launch a common Baltic balancing market from 2018," 2017. [Online]. Available: http://www.ast.lv/en/events/baltic-tsos-launchcommon-baltic-balancing-market-2018. [Accessed: 02-Feb-2018].

[7] G. Junghans, A. Silis, K. Marcina, and K. Ertmanis, "Role of Balancing Markets in Dealing with Future Challenges of System Adequacy Caused by Energy Transmission," Latv. J. Phys. Tech. Sci., vol. 57, no. 3, pp. 48-56, Jun. 2020.

[8] H. Holttinen, A. Tuohy, M. Milligan, V. Silva, S. Müller, and L. Soder, "The Flexibility Workout," IEEE Power Energy Mag., vol. 11, no. 6, pp. 53-62, 2013.

[9] N. O'Connell, P. Pinson, H. Madsen, and M. O'Malley, "Benefits and challenges of electrical demand response: A critical review," Renew. Sustain. Energy Rev., vol. 39, pp. 686-699, Nov. 2014.

[10] N. Good, K. A. Ellis, and P. Mancarella, "Review and classification of barriers and enablers of demand response in the smart grid," Renew. Sustain. Energy Rev., vol. 72, pp. 57-72, May 2017.

[11] Smart Grid Task Force, "Regulatory Recommendations for the Deployment of Flexibility - EG3 REPORT," 2015.

[12] N. G. Paterakis, O. Erdinç, and J. P. S. Catalão, "An overview of Demand Response: Key-elements and international experience," Renew. Sustain. Energy Rev., vol. 69, pp. 871-891, 2017.

[13] CIGRE, Short-term flexibility in power systems: drivers and solutions. Paris, 2020.

[14] SEDC, "Explicit Demand Response in Europe Mapping the Markets 2017," 2017.

[15] M. Muratori, B.-A. Schuelke-Leech, and G. Rizzoni, "Role of residential demand response in modern electricity markets," Renew. Sustain. Energy Rev., vol. 33, pp. 546553, May 2014.

[16] J.-H. Kim and A. Shcherbakova, "Common failures of demand response," Energy, vol. 36, no. 2, pp. 873-880, Feb. 2011.

[17] M. Shafie-khah, P. Siano, J. Aghaei, M. A. S. Masoum, F. Li, and J. P. S. Catalao, "Comprehensive Review of the Recent Advances in Industrial and Commercial DR," IEEE Trans. Ind. Informatics, vol. 15, no. 7, pp. 3757-3771, Jul. 2019.

[18] C. A. Cardoso, J. Torriti, and M. Lorincz, "Making demand side response happen: A review of barriers in commercial and public organisations," Energy Res. Soc. Sci., vol. 64, p. 101443, Jun. 2020. 
[19] B. Dupont, K. Dietrich, C. De Jonghe, A. Ramos, and R. Belmans, "Impact of residential demand response on power system operation: A Belgian case study," Appl. Energy, vol. 122, pp. 1-10, Jun. 2014.

[20] F. Shariatzadeh, P. Mandal, and A. K. Srivastava, "Demand response for sustainable energy systems: A review, application and implementation strategy," Renew. Sustain. Energy Rev., vol. 45, pp. 343-350, May 2015.

[21] S. Paiho et al., "Increasing flexibility of Finnish energy systems-A review of potential technologies and means," Sustain. Cities Soc., vol. 43, pp. 509-523, Nov. 2018.

[22] M. Barbero, C. Corchero, L. Canals Casals, L. Igualada, and F.-J. Heredia, "Critical evaluation of European balancing markets to enable the participation of Demand Aggregators," Appl. Energy, vol. 264, p. 114707, Apr. 2020.

[23] P. Kohlhepp, H. Harb, H. Wolisz, S. Waczowicz, D. Müller, and V. Hagenmeyer, "Large-scale grid integration of residential thermal energy storages as demand-side flexibility resource: A review of international field studies," Renew. Sustain. Energy Rev., vol. 101, pp. 527-547, Mar. 2019.

[24] "Feasibility study regarding cooperation between the Nordic and the Baltic power systems within the Nordic ENTSO-E pilot project on electricity balancing," 2014. [Online]. Available: http://www.ast.lv/files/ast_files/balansesana/STUDY REPORTNordic - Baltic cooperation in Electricity Balancing_112014_final.pdf.

[25] Pöyry Management Consulting (UK) Ltd, "Baltic's balance management model study and harmonisation plan towards EU energy markets model (including Nordic-Baltic balancing cooperation). A report to Elering," 2016. [Online]. Available: https://elering.ee/sites/default/files/attachments/Pöyry uuring.pdf.

[26] "Augstsprieguma tīkls" AS, "Annual statement of transmission system operator for the year 2016," 2017. [Online]. Available:

http://ast.lv/files/ast_files/gadaparskzinoj/TSO_Annual_Statement_2016.pdf. [Accessed: 28-Apr-2018].

[27] European Commission, Commission Regulation (EU) 2017/2195 of 23 November 2017 establishing a guideline on electricity balancing. 2017.

[28] A. McDonald, "Thermal Storage Device," US 2015/0055941 (A1), 2015.

[29] J.-M. Durand, M. J. Duarte, and P. Clerens, "Joint EASE/EERA recommendations for a European Energy Storage Technology Development Roadmap towards 2030,” 2013.

[30] G. Fraisse, C. Viardot, O. Lafabrie, and G. Achard, "Development of a simplified and accurate building model based on electrical analogy," Energy Build., vol. 34, no. 10, pp. 1017-1031, Nov. 2002.

[31] C. P. Underwood, "An improved lumped parameter method for building thermal modelling," Energy Build., vol. 79, pp. 191-201, Aug. 2014.

[32] A. P. Ramallo-González, M. E. Eames, and D. A. Coley, "Lumped parameter models for building thermal modelling: An analytic approach to simplifying complex multilayered constructions," Energy Build., vol. 60, pp. 174-184, May 2013.

[33] M. M. Gouda, S. Danaher, and C. P. Underwood, "Building thermal model reduction using nonlinear constrained optimization," Build. Environ., vol. 37, no. 12, pp. 12551265, Dec. 2002.

[34] N. Good, L. Zhang, A. Navarro-Espinosa, and P. Mancarella, "High resolution modelling of multi-energy domestic demand profiles," Appl. Energy, vol. 137, pp. 193$210,2015$.

[35] A. Rabl, "Parameter Estimation in Buildings: Methods for Dynamic Analysis of Measured Energy Use," J. Sol. Energy Eng., vol. 110, no. 1, pp. 52-66, 1988.

[36] G. Strbac, "Demand side management: Benefits and challenges," Energy Policy, vol. 36 , no. 12 , pp. 4419-4426, 2008. 
[37] N. Ritter et al., "H2020 RealValue D6.2 Market review report: socio-economic \& housing trends in selected countries," 2016. [Online]. Available: https://ec.europa.eu/research/participants/documents/downloadPublic?documentIds $=08$ 0166e5ad302011\&appId=PPGMS. [Accessed: 29-Jun-2020].

[38] AS "Sadales tīkls," "AS 'Sadales tīkls' gada pārskats 2016," 2017. [Online]. Available: https://www.sadalestikls.lv/files/newnode/parskati/ST_2016_gada_parskats.pdf.

[39] D. Bride and A. Zvaigzne, "Electricity Market Development in Latvia," J. Soc. Sci., vol. 1, no. 8, pp. 5-19, 2016.

[40] European Commission, "Europe leads the global clean energy transition: Commission welcomes ambitious agreement on further renewable energy development in the EU," 2018. .

[41] T. J. Hammons, "Integrating renewable energy sources into European grids," Int. J. Electr. Power Energy Syst., vol. 30, no. 8, pp. 462-475, Oct. 2008.

[42] J. a. P. Lopes, N. Hatziargyriou, J. Mutale, P. Djapic, and N. Jenkins, "Integrating distributed generation into electric power systems: A review of drivers, challenges and opportunities," Electr. Power Syst. Res., vol. 77, no. 9, pp. 1189-1203, Jul. 2007.

[43] SEDC, "Explicit and Implicit Demand-Side Flexibility Complementary Approaches for an Efficient Energy System Explicit and Implicit Demand-Side Flexibility: Complementary Approaches for an Efficient Energy System," no. September, 2016.

[44] M. H. Albadi and E. F. El-Saadany, "A summary of demand response in electricity markets," Electr. Power Syst. Res., vol. 78, no. 11, pp. 1989-1996, Nov. 2008.

[45] M. H. Albadi and E. F. El-Saadany, "Demand Response in Electricity Markets: An Overview," in 2007 IEEE Power Engineering Society General Meeting, 2007, pp. 1-5.

[46] N. Prüggler, "Economic potential of demand response at household level-Are CentralEuropean market conditions sufficient?," Energy Policy, vol. 60, pp. 487-498, Sep. 2013.

[47] M. Behrangrad, "A review of demand side management business models in the electricity market," Renew. Sustain. Energy Rev., vol. 47, pp. 270-283, Jul. 2015.

[48] L. Gkatzikis and I. Koutsopoulos, "The Role of Aggregators in Smart Grid Demand Response Markets," IEEE J. Sel. Areas Commun., vol. 31, no. 7, pp. 1247-1257, 2013.

[49] A. Rautiainen et al., "Attractiveness of demand response in the Nordic electricity market - Present state and future prospects," in 2017 14th International Conference on the European Energy Market (EEM), 2017, pp. 1-6.

[50] L. Sadovica, K. Marcina, V. Lavrinovics, and G. Junghans, "Facilitating energy system flexibility by demand response in the Baltics - Choice of the market model," in 2017 IEEE 58th International Scientific Conference on Power and Electrical Engineering of Riga Technical University (RTUCON), 2017, pp. 1-6.

[51] "Augstsprieguma tīkls" AS, Elering AS, and Litgrid UAB, "Demand response through aggregation - a harmonized approach in Baltic region," 2017.

[52] M. Muratori and G. Rizzoni, "Residential Demand Response: Dynamic Energy Management and Time-Varying Electricity Pricing," IEEE Trans. Power Syst., vol. 31, no. 2, pp. 1108-1117, 2016.

[53] H. C. Gils, "Economic potential for future demand response in Germany - Modeling approach and case study," Appl. Energy, vol. 162, pp. 401-415, 2016.

[54] F. Wang, H. Xu, T. Xu, K. Li, M. Shafie-khah, and J. P. S. Catalão, "The values of market-based demand response on improving power system reliability under extreme circumstances," Appl. Energy, vol. 193, pp. 220-231, May 2017.

[55] G. Bianchini, M. Casini, A. Vicino, and D. Zarrilli, "Demand-response in building heating systems: A Model Predictive Control approach," Appl. Energy, vol. 168, pp. 159-170, 2016. 
[56] A. Arteconi, D. Patteeuw, K. Bruninx, E. Delarue, W. D'haeseleer, and L. Helsen, "Active demand response with electric heating systems: Impact of market penetration," Appl. Energy, vol. 177, pp. 636-648, 2016.

[57] F. De Ridder, M. Hommelberg, and E. Peeters, "Demand side integration: four potential business cases and an analysis of the 2020 situation," Eur. Trans. Electr. Power, vol. 21, no. 6, pp. 1902-1913, Sep. 2011.

[58] E. Moreno, O. A. Gonzalez, and A. Pavas, "Demand flexibility assessment for residential customers," in 2017 IEEE Workshop on Power Electronics and Power Quality Applications (PEPQA), 2017, pp. 1-5.

[59] B. Neupane, L. Šikšnys, and T. B. Pedersen, "Generation and Evaluation of Flex-Offers from Flexible Electrical Devices," Proc. Eighth Int. Conf. Futur. Energy Syst. - eEnergy '17, pp. 143-156, 2017.

[60] Z. Yahia and A. Pradhan, "Optimal load scheduling of household appliances considering consumer preferences: An experimental analysis," Energy, vol. 163, pp. 15-26, 2018.

[61] Z. Ma, J. Billanes, and B. Jørgensen, "Aggregation Potentials for Buildings - Business Models of Demand Response and Virtual Power Plants," Energies, vol. 10, no. 10, p. 1646, Oct. 2017.

[62] M. Brolin, "Aggregator trading and demand dispatch under price and load uncertainty," in 2016 IEEE PES Innovative Smart Grid Technologies Conference Europe (ISGTEurope), 2016, pp. 1-6.

[63] D. T. Nguyen, M. Negnevitsky, and M. De Groot, "Modeling load recovery impact for demand response applications," IEEE Trans. Power Syst., vol. 28, no. 2, pp. 12161225, 2013.

[64] M. Vallés, A. Bello, J. Reneses, and P. Frías, "Probabilistic characterization of electricity consumer responsiveness to economic incentives," Appl. Energy, vol. 216, no. September 2017, pp. 296-310, 2018.

[65] H. Janssen, "Monte-Carlo based uncertainty analysis: Sampling efficiency and sampling convergence," Reliab. Eng. Syst. Saf., vol. 109, pp. 123-132, 2013.

[66] "MATLAB." The MathWorks Inc, Natick, Massachusetts.

[67] J. L. Mathieu, M. Kamgarpour, J. Lygeros, G. Andersson, and D. S. Callaway, "Arbitraging Intraday Wholesale Energy Market Prices With Aggregations of Thermostatic Loads," IEEE Trans. Power Syst., vol. 30, no. 2, pp. 763-772, Mar. 2015.

[68] V. Trovato, F. Teng, and G. Strbac, "Value of thermostatic loads in future low-carbon Great Britain system," in 2016 Power Systems Computation Conference (PSCC), 2016, pp. 1-7.

[69] A. M. Mathew and R. Menon, "Assessment of demand response capability with thermostatic loads in residential sector," in 2015 International Conference on Power, Instrumentation, Control and Computing (PICC), 2015, pp. 1-5. 